\title{
Evaluation of the spoilage potential of bacteria isolated from spoiled raw salmon (Salmo salar) fillets stored under modified atmosphere packaging
}

\author{
Sabrina Macé ${ }^{\mathrm{a}, \mathrm{b}, \mathrm{c}}$, Jean-Jacques Joffraud ${ }^{\mathrm{c}, *}$, Mireille Cardinal ${ }^{\mathrm{c}}$, Mariya Malcheva ${ }^{\mathrm{a}, \mathrm{b}, \mathrm{c}}$, \\ Josiane Cornet ${ }^{c}$, Valérie Lalanne ${ }^{\mathrm{d}, \mathrm{e}}$, Frédérique Chevalier $^{\mathrm{c}}$, Thierry Sérot ${ }^{\mathrm{d}, \mathrm{e}}$, Marie-France Pilet ${ }^{\mathrm{a}, \mathrm{b}}$, \\ Xavier Dousset ${ }^{\mathrm{a}, \mathrm{b}}$
}

\author{
a LUNAM Université, ONIRIS, Univ Nantes, UMR1014 Secalim, Nantes, F-44307, France \\ ${ }^{b}$ INRA, Nantes, F-44307, France \\ c Ifremer, Laboratoire Science et Technologie de la Biomasse Marine, BP 21105, 44311, Nantes Cedex 3, France \\ d LUNAM Université, ONIRIS, Univ Nantes, UMR 6144 GEPEA, Flavor Unit, F 44307, France \\ e CNRS, Nantes, F-44307, France \\ *: Corresponding author : Jean-Jacques Joffraud, Tel.: (+33) 240374284 ; fax: (+33) 240374071 ; \\ email address : jean.jacques.joffraud@ifremer.fr
}

\begin{abstract}
:
The spoilage potential of eight bacterial groups/species (Serratia spp., Hafnia alvei, Brochothrix thermosphacta, Carnobacterium maltaromaticum, Shewanella baltica, Lactococcus piscium, Photobacterium phosphoreum, "other Enterobacteriaceae" [containing one strain of Moellerella sp., Morganella sp. and Pectobacterium sp.]) isolated from spoiled raw salmon fillets stored under modified atmosphere packaging (MAP) was evaluated by inoculation into sterile raw salmon cubes followed by storage for 12 days at $8^{\circ} \mathrm{C}$. Microbial growth and sensory changes were monitored during the storage period. The dominant spoilage bacteria were $C$. maltaromaticum, $H$. alvei and $P$. phosphoreum. In order to further characterize their spoilage potential and to study the effect of their interactions, each of these 3 specific spoilage organisms (SSO) and two mixed-cultures, C. maltaromaticum/H. alvei and C. maltaromaticum/P. phosphoreum were tested in the sterile salmon model system using a combination of complementary methods: molecular (PCR-TTGE), sensory, chemical and conventional microbiological analyses. It was concluded that, in the mixed-culture inoculated samples, the dominant species determined the spoilage characteristics. The volatile fraction of $P$. phosphoreum inoculated samples was analyzed by solid-phase microextraction (SPME) followed by gas chromatography coupled to mass spectrometry (GC-MS). Among the specific volatile compounds present on $P$. phosphoreum spoiled inoculated samples, acetic acid was correlated with sensory analysis and can be proposed as a raw salmon spoilage marker.
\end{abstract}

\section{Highlights}

Spoilage potential of 8 bacterial groups isolated from spoiled salmon was evaluated. Specific spoilage organisms were identified among these bacterial groups. Spoilage abilities and bacterial interactions of 3 dominant spoilers were further characterized. On mixed-culture inoculated samples, spoilage characteristics are imposed by the dominant species.

Keywords: Spoilage potential ; Bacterial interaction ; Specific spoilage organism ; Atlantic salmon ; Volatile compounds 


\section{Introduction}

Modified atmosphere packed (MAP) fresh fish is increasingly popular in Europe and widely sold by supermarkets as a chilled ready-to-use product. This type of packaging increases the shelf life of seafood products by inhibiting many microorganisms, including Gramnegative aerobic bacteria (Gram and Huss, 1996; Sivertsvik et al., 2002), and also makes transport and distribution easier. The spoilage microbiota of a packaged food product depends on the endogenous microflora present on the products, with post-harvest processing, the packaging method (MAP, vacuum, aerobic, etc.) and storage temperature being among the most important parameters (Sivertsvik et al., 2002). Some studies concerning Atlantic salmon (Salmosalar) or King salmon (Oncorhynchustshawytscha) under MAP have been carried out to determine changes in quality during storage or to propose some technological features to improve shelf life (de la Hoz et al., 2000; Fletcher et al., 2002; Sivertsvik et al., 2003; Hansen et al., 2009; Schirmer et al., 2009). In these studies, the changes in microbial parameters, such as total flora, Enterobacteriaceae, and Lactic Acid Bacteria (LAB), were usually monitored during storage but the detailed composition of the microbiota has been less investigated. Rudi and colleagues (Rudi et al., 2004) reported Carnobacterium maltaromaticum, Carnobacterium divergens and Brochothrix thermosphacta as the dominant flora in salmon fillets packed in an atmosphere consisting of $60 \% \mathrm{CO}_{2}$ and $40 \% \mathrm{~N}_{2}$ while another study (Powell and Tamplin, 2012) explored microbial communities found on Australian MAP Atlantic salmon fillets and reported a domination of Carnobacterium spp. and Shewanella spp. together with a variety of other genera present in small numbers after 15 days of storage. Our recent study (Macé et al., 2012) of salmon steaks stored under vacuum or MAP $\left(50 \% \mathrm{CO}_{2}\right.$ and $\left.50 \% \mathrm{~N}_{2}\right)$ identified different dominant bacterial groups or species at the time of spoilage, including members of LAB (Lactococcuspiscium), Gram-negative fermentative bacteria (Photobacterium phosphoreum) and Enterobacteriaceae (Serratiaspp.).

At the onset of spoilage, the product contains some bacteria that are involved in spoilage, the so-called specific spoilage organisms (SSO), and others which grow without causing unpleasant changes (Gram and Huss, 1996; Dalgaard, 2000; Gram et al., 2002). These SSO may be present in low numbers initially and only constitute a small fraction of the processed seafood microbiota at the beginning of the storage period. To identify the SSO among the bacterial groups present at the time of spoilage, some authors have compared the impact of bacterial isolates on the chemical and sensory characteristics of the products with those of naturally spoiled products. These experiments enabled the spoilage potential of microorganisms to be determined, i.e. their ability to produce metabolites resulting in offodours or off-flavours (Dalgaard, 2000; Gram and Dalgaard, 2002; Dalgaard, 2006).

In the present study, a similar approach was used to identify the SSO dominating MAP stored raw salmon (Salmosalar) fillets. Clearly, improving knowledge of the SSO for specific seafood products will lead to the development of better detection methods, shelf life predictions, and preservation techniques thus reducing losses due to spoilage (Dalgaard, 2000).

Microorganisms in seafood products can interact in several ways including antagonism, where a selective advantage is created for some of the microorganisms, and metabiosis, which describes the reliance by an organism on the metabolic activity of another microorganism to produce a favourable environment to stimulate growth (Gram and Huss, 1996; Dalgaard, 2006). This suggests that interactions between dominant bacterial species may play a role in spoilage.

In order to identify the SSO for MAP stored raw salmon (Salmosalar) fillets, a two-step approach was taken: first, the ability to spoil was investigated for eight different bacterial 
groups previously isolated from spoiled salmon fillets; secondly, the spoilage potential of the bacterial groups found to be the strongest spoilers in the previous screening was further characterized. The inoculation challenge tests were conducted in an ionized sterile raw salmon model system by monitoring bacterial and sensory changes throughout the storage period. To investigate the interaction among spoilage bacteria, binary cultures combining two of the main spoilage bacteria were inoculated into the salmon model system and characterized by molecular (PCR-TTGE), sensory, chemical and conventional microbiological analyses. Volatile microbialmetabolitescan cause the formation of spoilage off-odours(Joffraud et al., 2001; Olafsdottir et al., 2005; Wierda et al., 2006; Jaffrès et al., 2009). These volatiles may be useful as quality indicators as they will be related to the number of SSO present in the product. In order to try and identify a suitable MAP raw salmon spoilage marker, the volatile fraction released by the dominant P.phosphoreum isolates inoculated on raw salmon was analysed by solid phase micro-extraction (SPME) and gaschromatography coupled to mass spectrometry (GC-MS).

\section{Materials and Methods}

\subsection{Bacterial strains}

All strains tested in this study were previously isolated from 3 batches (A, B or C) of raw spoiled salmon fillets under MAP. These three batches were obtained from à local plant after packing. The samples were stored at $4^{\circ} \mathrm{C}$ for 3 days then at $8^{\circ} \mathrm{C}$ for 7 days after a break of 2 hours at $20^{\circ} \mathrm{C}$, according to the EU shelf life protocol. Sensorial analysis and enumeration of bacterial groups were performed during storage after 8 and 12 days on each batch following protocol described by Macé et al (2012). At the onset of spoilage (determined sensory analysis panellists), strains were isolated from batch $C$ after 8 days and from batch $A$ and $B$ after 12 days of storage. Isolates were maintained as frozen stocks at $-80^{\circ} \mathrm{C}$ in a cryoprotective medium containing glycerol (20\%). Strains MIP 2415 and MIP 2418 were isolated previously from spoiled salmon during another research project. All strains were identified by $16 \mathrm{~S}$ rRNA gene partial sequencing of about $700 \mathrm{bp}$ (data not shown) and found to belong to different genera or species distributed in eight different bacterial groups: Serratiaspp., Hafniaalvei,B. thermosphacta, C. maltaromaticum, Shewanellabaltica, $L$. piscium, P. phosphoreum, "other Enterobacteriaceae" (containing one strain ofMoellerellasp., Morganellasp.andPectobacteriumsp.). Each group was represented by several isolates of the same species (from 2 to 6 depending on the group) except the "other Enterobacteriaceae" group which was composed of 3 different species (Table 1).

\subsection{Challenge tests}

\subsubsection{Sampling for preliminary characterization of spoilage potential}

Raw salmon flesh cubes $(7 \mathrm{~kg})$ were prepared from fresh salmon (Salmosalar) fillets essentially following the protocol of Joffraud and colleagues (Joffraud et al., 1998). The fish were washed in $5 \% \mathrm{Na}_{2} \mathrm{CO}_{3}$ to remove outer slime. After removing the head and tail, the skin surface and gut cavity were washed again in $5 \% \mathrm{Na}_{2} \mathrm{CO}_{3}$ and $2 \%$ formalin. The fish were hand-filleted and skinned using knives and cutting boards sanitized in chlorine solution before being rinsed in $1 \%$ chlorinated water. Finally, fillets were rinsed with sterile water and cut into cubes taking between 1 and $2 \mathrm{~cm}^{3}$. These were packed under vacuum in $1 \mathrm{~kg}$ bags, frozen at $-80^{\circ} \mathrm{C}$ and sterilized by ionization treatment (gamma rays, $5 \mathrm{KGy}$ ) at the lonisoscompany (Pouzauge, France). The sterilized matrix was kept at $-80^{\circ} \mathrm{C}$ until the start of the experiments and thawed at $4^{\circ} \mathrm{C}$ for $24 \mathrm{~h}$ before commencing the experiments. Strains were pre-cultured individually in brain heart infusion broth (BHI) (Difco Laboratories, Detroit, 
MI, USA) at $20^{\circ} \mathrm{C}\left(15^{\circ} \mathrm{C}\right.$ for P.phosphoreum) until their maximal concentration was reached (1-3 d). Mixtures of several isolates belonging to the same species were pooled in a sterile vial and diluted in sterile peptone water $(0.85 \% \mathrm{NaCl}$ and $0.1 \%$ peptone $)$, in order to achieve an inoculation mixture containing 5 Log $\left(C F U . \mathrm{mL}^{-1}\right)$. Two $\mathrm{mL}$ of each inoculation mixture were sprayed onto a batch of approximately $750 \mathrm{~g}$ of sterile raw salmon cubes placed in a laminar flow hood to reach an inoculated level of 3 Log $\left(\right.$ CFU.g $\left.{ }^{-1}\right)$. A control was prepared by inoculating the sterile salmon matrix with sterile water. Each batch of inoculated salmon cubes and the non-inoculated control salmon cubes were placed in 3 plastic trays, each containing $\sim 250 \mathrm{~g}$ portions (one for each analysis date), and packed under modified atmosphere $\left(50 \% \quad \mathrm{CO}_{2}\right.$ and $\left.50 \% \quad \mathrm{~N}_{2}\right)$ using a Multivac T 200 machine (Hagenmüller, Wolfertschwenden, Germany) and a low gas permeability film (low density polyethylene, LDPE, LINPAC Plastics, permeability: $\mathrm{O}_{2}<5 \mathrm{~cm}^{3} / \mathrm{m}^{2} .24$ h.bar, $\mathrm{CO}_{2}<25 \mathrm{~cm}^{3} / \mathrm{m}^{2} .24$ h.bar). All batches of inoculated salmon cubes and the control were stored at $8^{\circ} \mathrm{C}$ for 12 days. Sensory, chemical and microbiological analyses were carried out after 1, 7 and 12 days.

\subsubsection{Sampling for further characterization of spoilage potential}

Raw salmon flesh cubes (Salmosalar) sizing between 1 and $2 \mathrm{~cm}^{3}$ were prepared from fillets $(21 \mathrm{~kg})$ in the same conditions as previously described. For this part, 3 strain groups, C. maltaromaticum, $H$. alvei and $P$. phosphoreum, determined as being the main spoilers by the first challenge test, were inoculated singly or in co-cultures. The two binary cultures consisted of one mix with $C$. maltaromaticum and $H$. alvei and another with $C$. maltaromaticum and $P$. phosphoreum. Cultures were diluted as previously described, mixed and inoculated $(10 \mathrm{~mL})$ on approximately $3500 \mathrm{~g}$ of sterile raw salmon cubes to achieve initial levels of 3 Log $\left(\right.$ CFU. $\left.\mathrm{g}^{-1}\right)$. A non-inoculated control was also prepared. Each different batch of inoculated salmon cubes and the control salmon cubes were divided into 15 plastic trays (around $233 \mathrm{~g}$ portions) and packaged as described before. All batches of inoculated salmon cubes and the non-inoculated control were stored at $8^{\circ} \mathrm{C}$ for 11 days. After $1,4,6,8$ and 11 days, samples were subjected to sensory, chemical and microbiological analyses.

\subsection{Enumeration of inoculated strains}

At each sampling date of the preliminary characterization, one packet of the different batches was used for microbiological analysis. A $30 \mathrm{~g}$ portion was aseptically weighed and pooled in $120 \mathrm{ml}$ of sterile peptone water $(0.85 \% \mathrm{NaCl} ; 0.1 \%$ peptone $)$ in a sterile plastic bag and blended with a stomacher 400 (Seward Medical, London, UK) for 2 min. Several appropriate 10 -fold dilutions of the analysis solution were carried out in sterile physiological saline solution and $0.1 \mathrm{ml}$ of each was spread-plated. Inoculated isolates were enumerated on Brain Heart Infusion Agar medium (BHI). Petri plates were kept at $20^{\circ} \mathrm{C}$ for $2-5$ days.

For the further characterization of the spoilage potential, three packets of the different batches were used, at each sampling date, for microbiological analysis. From each package, a $10 \mathrm{~g}$ portion was aseptically weighed and the three portions were pooled, treated and enumerated as described previously. For co-cultured groups, the species were distinguished on $\mathrm{BHI}$ plates by their morphological differences. 


\subsection{Sensory analysis}

\subsubsection{Panel}

Sensory analysis was carried out with internal panel of IFREMER, experienced in seafood evaluation and especially in salmon (Macé et al., 2012). Preliminary sessions were organized with 21 panellists before to start the experiment. Three sessions were focused on odour description with a range of products stored at $+4^{\circ} \mathrm{C}$ for different time $(0,8$ and 12 days $)$ in order to present different levels of spoilage. Panellists were asked to describe the odour characteristics and after a step of selection for discriminative and relevant descriptors, a discussion with the panel members allowed to check a consensus on attribute definition. Two other sessions were organized to train the panel on the scoring of these attributes. A third session was focused on harmonization between panellists on the level of spoilage attributed to the same kind of products during the description step. The training step was also completed with regular sniffing of odour references already identified as odours potentially produced during the spoilage process. Finally, 14 trained panellists, selected according to their sensory capacities participated to the experiment, 9 for the preliminary characterization of the spoilage potential and the 14 for the further characterization step.

\subsubsection{Sampling preparation}

For the preliminary characterization of spoilage potential, one packet per batch was opened for each assessor while three packets per batch were used for further characterization. For each assessor, $25 \mathrm{~g}$ portions were placed in glass bowls with lids to keep the odours intact.

\subsubsection{Sensory tests}

\subsubsection{Preliminary characterization of spoilage potential}

The following tests were used to sort the species initially by their spoilage potential. Panellists classified each sample according to its spoilage level (NS: non-spoiled; LS: lightly spoiled; SS: strongly spoiled) and chose two main characteristic odours among the following descriptors: marine/iodine, nothing, fatty fish, salmon, sardine, grass, butter/caramel, pyrrolidine, acid/vinegar, sour/fermented, amine, cabbage and feet/cheese. The sensory descriptors were selected during preliminary sessions.At the end of the evaluation, the products were considered strongly spoiled when at least $50 \%$ of the assessors classified them as such.

\subsubsection{Further characterization of the spoilage potential}

A quantitative descriptive analysis (QDA) described by Stone and Sidel (2004) was used to determine sensory profile (ISO, 2003) for each salmon product inoculated with each species and co-cultured species. First, panellists had to score on a continuous scale from 0 to 10 , the spoilage level and then the following appropriate odour descriptors: overall intensity, fatty fish, butter/caramel, acid/vinegar, sour/fermented, amine, pyrrolidine and feet/cheese. These descriptors were those considered pertinent during the preliminary characterization of spoilage potential. 


\subsubsection{Evaluation conditions and sample presentation}

Sessions were performed in individual partitioned booths, as described in the procedure NF V-09-105 (AFNOR, 1987), equipped with a computerised system (Fizz, Biosystèmes, Couternon, France). All the samples were frozen after microbiological analysis and were assessed during 3 sessions for preliminary characterization of their spoilage potential and during 5 sessions for further characterization. Inoculated products were assigned digit numbers, randomized and presented simultaneously to the panellist after 1 hour in an oven at $18^{\circ} \mathrm{C}$. Frequencies of citation were calculated for odour characteristics in the preliminary characterization of spoilage potential. Principal component analysis (PCA) with standardization was performed on the means of the scores for each sensory descriptor and spoilage intensity. Multivariate data processing was carried out with UniwinPlus 6.1 software (Sigma Plus).

\subsection{Chemical analysis}

These analyses were only performed in the further characterization stage. At each sampling date, $150 \mathrm{~g}$ of raw inoculated salmon flesh was homogenized in a Waring Blender (New Hartford, CO, USA). From $100 \mathrm{~g}$ of the homogenized milling, Total Volatile Basic Nitrogen (TVBN) and Trimethylamine (TMA) were measured in duplicate by the Conway micro diffusion method (Conway and Byrne, 1933). The $\mathrm{pH}$ value was measured with a $\mathrm{pH}$ meter (Mettler Delta, AES, Combourg, France) in the five-fold-diluted flesh prepared as described above for microbiological analysis.

\subsection{Analysis of volatile compounds}

During further characterization of spoilage potential, at day 1 and day 8 , volatile compounds produced by the non-inoculated control sample and the $P$. phosphoreum inoculated sample were analysed using a gas chromatography device, model GC 7890A, Agilent (Agilent Technologies, Santa Clara, USA) coupled with a mass spectrometer 5975C VL (Agilent) and flame ionization detector after solid-phase microextraction (SPME/GC-MS-FID). The extraction and injection processes were performed automatically using an autosampler MPS 2 (Gerstel, Mülheim, Germany). Briefly, a 5-g portion of salmon sample was weighed into a 20- $\mathrm{ml}$ vial with a polypropylene screw-on cap and a PTFE/silicone septum (Supelco, Bellefonte, PA, USA) to make it airtight. The vial was heated at $40^{\circ} \mathrm{C}$ for 40 min to equilibrate the system. The SPME fibre, $85 \mu$ mcarboxen/polydimethylsiloxane Stable Flex ${ }^{\mathrm{TM}}$ (Supelco), was inserted through the septum and exposed in the headspace of the vial for $30 \mathrm{~min}$, to allow absorption of the volatile compounds onto the SPME fibre. This was then introduced into the injector port of the gas chromatograph for $5 \mathrm{~min}$ in splitless mode, set at $280^{\circ} \mathrm{C}$, in order to desorb the volatile compounds. The desorbed components were analysed on a capillary column Agilent J\&W DB- $5 \mathrm{~ms}$ (30 m length $\times 0.25 \mathrm{~mm}$ internal diameter $\times 0.5 \mu \mathrm{m}$ film thickness). Helium was used as carrier gas with a flow of $1.3 \mathrm{ml} / \mathrm{min}$ and the oven temperature was programmed as follows: $40^{\circ} \mathrm{C}$ for $5 \mathrm{~min}$, then ramped at $3^{\circ} \mathrm{C} \mathrm{min}^{-1}$ to 140 ${ }^{\circ} \mathrm{C}$, then ramped at $6^{\circ} \mathrm{C} \mathrm{min}{ }^{-1}$ to $240^{\circ} \mathrm{C}$, and held for $5 \mathrm{~min}$. Molecules of volatile compounds were detected by FID and a mass selective detector. The detector operated in a mass range between 33 and 300 with a scan rate of 2 scans/s. Compounds were identified by comparison of mass spectra with a reference database (Wiley 6.0), and by comparison of mass spectra and linear retention indexes (LRI) with those of standards injected in the same conditions. 
Mean values of samples peak areas were compared by analysis of variance to identify specific spoilage volatile compounds. ANOVA processing was performed with StatgraphicsPlus 5.1 software (Statistical Graphics Corp.). Data were reported as log (peak area/g) for each specific compound detected.

\subsection{TTGE analysis on co-cultured inoculated samples}

\subsubsection{Direct bacterial DNA extraction from the salmon matrix inoculated with mixed groups}

The suspension prepared for bacteriological analysis was used to obtain molecular fingerprints from the salmon matrix inoculated with co-culture strain groups. Bacterial DNA extraction was performed as described previously (Macé et al., 2012).

\subsubsection{TTGE analysis}

Bacterial DNA from the salmon inoculated matrix was analysed by PCR-TTGE. Primers V3P2 and V3P3-GC-Clamp were used to amplify V3 region (194 bp) PCR-amplicons as described previously (Jaffrès et al., 2009). The size of the PCR products was determined in a $1.5 \%$ (w/v) agarose gel (Invitrogen) using an exACTGene 100 bp PCR DNA Ladder (Fisher Scientific, Illkirch, France). The PCR products obtained from the V3 16S rDNA fragment amplification were subjected to TTGE gel analysis, which was performed as previously described by Jaffrès et al. (2009). Standardization, analysis and comparison of TTGE fingerprints were monitored using BioNumerics Software, version 6.0 (Applied Maths NV, Sint-Martens-Latem, Belgium) as described by Macé et al(2012).

\section{Results}

\subsection{Preliminary characterization of spoilage potential}

\subsubsection{Enumeration of the different bacterial groups}

Fig. 1 shows the mean growth pattern of the eight different bacterial groups. The ionized control was below the enumeration threshold $\left(0.7 \mathrm{Log}\left(\mathrm{CFU} . \mathrm{g}^{-1}\right)\right)$ until the end of storage (data not shown). The initial counts of the inoculated samples were about 3 Log (CFU.g ${ }^{-1}$ ) as expected. Bacterial groups grew to between 6.7 and 8.7 Log (CFU.g ${ }^{-1}$ ) after 7 days of storage except for the $P$. phosphoreum group which only reached 4 Log (CFU. $\left.g^{-1}\right)$.

At the end of storage, all the bacterial groups rose to levels ranging between 6.6 ( $P$. phosphoreum) and 9 Log (CFU.g $\left.{ }^{-1}\right)$ (C. maltaromaticum).

\subsubsection{Sensory characteristics of inoculated raw salmon}

After 1 day of storage, inoculated samples were considered non-spoiled by $66.7 \%$ to $89 \%$ of the panellists, depending on the bacterial group inoculated (Table 2) except for the sample inoculated with $L$. piscium which was scored as lightly spoiled by $55.6 \%$ of the panellists. At day 7, the spoilage of inoculated samples had increased and samples inoculated with 3 bacterial groups, $\mathrm{H}$. alvei, C. maltaromaticum or P. phosphoreum, were considered strongly spoiled by 66.7 to $100 \%$ of the panellists. After 12 days of storage, 5 samples inoculated with $B$. thermosphacta, the "other Enterobacteriaceae"group, $H$. alvei, C. maltaromaticum or $P$. 
phosphoreum were assessed as strongly spoiled whereas the one inoculated with $L$. piscium, S. baltica or Serratia spp. remained lightly spoiled. The ionized control sample was not considered spoiled during all the storage period.

After 7 or 12 days of storage, the inoculated batches exhibited different typical characteristic odours. For each bacterial group, the main sample off-odours, as noted by at least 3 panellists, were acid, amine, butter, cabbage, fatty fish, feet/cheese, pyrrolidine and sour (Table 3).

Bacterial isolates belonging to $H$. alvei, C. maltaromaticum and $P$. phosphoreum were responsible for the strongest spoilage odours observed after 7 days and were considered to be the main spoilage bacteria in the product. Hence, their spoilage potential was subjected to further characterization.

\subsection{Further characterization of the spoilage potential}

\subsubsection{Spoilage potential of single-species groups}

The results of viable counts of inoculated salmon samples with the 3 different bacterial groups and the 2 co-cultures are shown in Figure 2. The ionized control presented a bacterial count under the threshold of 0.7 Log $\left(\mathrm{CFU} \cdot \mathrm{g}^{-1}\right)$ throughout the storage and was thus considered a sterile matrix. It can be noted that the control sample was scored "non-spoiled" during all the storage with grades between 0 and 1 (Fig. 3). The principal component analysis (PCA) presented in Fig. 4 was performed on the mean scores of profiling tests and synthesises the evolution of the main odour characteristics for inoculated samples. The simultaneous projection of samples and sensory descriptors is shown on the first 1-2 plane (Fig. 4 A). The first axis (62.9\% of the information) enables the spoilage level of each sample to be visualized. It divides the typical odours of freshness, on the left, of non-spoiled products from the spoiled samples, on the right, around salmon typical off-odours with amine, sour, feet/cheese, etc. The second axis, representing $16.5 \%$ of information, enables the visualization of samples presenting the same spoilage characteristics. All the control samples, from day 1 to day 11, are on the left part of this figure, surrounding the unspoiled inoculated samples, and presented a slightly fatty fish odour characteristic of freshness

Concerning the inoculated samples, C. maltaromaticum counts (Fig. $2 \mathrm{~A}$ and B) were initially 3 Log $\left(\right.$ CFU. $\left.\mathrm{g}^{-1}\right)$ and reached $8.9 \mathrm{Log}\left(\mathrm{CFU} . \mathrm{g}^{-1}\right)$ after 11 days of storage. The sample spoilage level began to increase from 6 days of storage to reach a maximum of about 5.6 at the end of storage (Fig. 3) and exhibited mainly butter and feet cheese odours after 8 and 11 days of storage (Fig. 4 A). No TVBN production was induced by $C$. maltaromaticum compared to the control (Fig. $5 \mathrm{~A}$ ) and only a small amount of TMA (7.8 mg-N TMA $100 \mathrm{~g}^{-1}$ ) was produced at the end of storage (Fig. 5 B).

P. phosphoreumand H. alvei were inoculated at around 2 Log (CFU.g $\left.{ }^{-1}\right)$ (Fig. 2 A and B). A rapid growth was observed for $P$. phosphoreum, reaching more than 6.5 Log (CFU.g $\left.{ }^{-1}\right)$ after 4 days of storage. On the $8^{\text {th }}$ day, a decrease of between 4 and 5 Log $\left(C F U . g^{-1}\right)$ was noticed followed by a rise to 6.8 Log $\left(\right.$ CFU.g ${ }^{-1}$ ) after 11 days. These samples obtained the sensory spoilage grade of 7 on day 4 and stayed strongly spoiled throughout the storage period (Fig. 3). Samples were characterized by sour, amine and acid odours from day 4 which remained until the end of storage (Fig. 4). An increase in TVBN and TMA production was observed during storage with a maximal level of $38 \mathrm{mg}-\mathrm{N}$ TVBN $100 \mathrm{~g}^{-1}$ and $21 \mathrm{mg}-\mathrm{N}$ TMA $100 \mathrm{~g}^{-1}$, respectively, at the end of storage (Fig. 5).

The $H$. alvei group reached its maximum growth level after 11 days of storage with 8.3 Log $\left(\mathrm{CFU} . \mathrm{g}^{-1}\right)$. It showed a different spoilage profile compared to the others: the samples were 
considered unspoiled until the $6^{\text {th }}$ day of storage, lightly spoiled after the $8^{\text {th }}$ day with a grade of 3 and strongly spoiled with a grade of 6 after 11 days of storage. The typical pyrrolidine odour of samples spoiled with $H$. alveils underlined by the third axis (11.2\% of information) on Fig. 4 B. At their time of spoilage (day 11), the samples exhibited an increase in TVBN production of $51 \mathrm{mg}-\mathrm{N}$ TVBN $100 \mathrm{~g} \mathrm{~g}^{-1}$ and the final production of TMA was about $14 \mathrm{mg}-\mathrm{N}$ TMA $100 \mathrm{~g}^{-1}$.

The $P$. phosphoreum group, considered the most spoiling bacterial group tested in this work, was included in the volatile compound research by SPME/GC-MS-FID. Approximately thirty components were identified in the sample tested. Statistical treatment was used to compare the non-inoculated control sample stored 1 and 8 days, newly $P$. phosphoreum inoculated sample (1 day of storage) and spoiled $P$. phosphoreum sample. Hence, twelve compounds exhibiting a specific behaviour on the spoiled sample tested were determined (Table 4). Ten of these were only detected in samples spoiled by $P$. phosphoreum: isobutyraldehyde; acetic acid; ethyl acetate; butanal, 2-methyl; butanal, 3-methyl; 1 propanol-2 methyl; 3-methyl-2butanol; benzaldehyde; benzene acetaldehyde; benzene ethanol. 3-hydroxybutanone (acetoin) production was very slightly increased in $P$. phosphoreum samples after 8 days of storage compared to the three other samples $(p<0.05)$. Antioxidant BHT presented a slight decrease in the P. phosphoreum spoiled samples $(p<0.05)$.

\subsubsection{Spoilage potential of mixed-species groups}

In the presence of $P$. phosphoreum, C. maltaromaticum growth was inhibited from day 6 (compared to the monoculture) and its count reached only 7.6 Log (CFU.g ${ }^{-1}$ ) at the end of storage (Fig. 2 A). On the other hand, $P$. phosphoreum in co-culture presented the same typical kinetics as when alone in the matrix. Samples inoculated with $P$. phosphoreum and $C$. maltaromaticum gave the maximum production of TVBN and TMA (about 52 mg-N TVBN $100 \mathrm{~g}^{-1}$ and $24 \mathrm{mg}-\mathrm{N}$ TMA $100 \mathrm{~g}^{-1}$ ) observed among all the samples tested in this study (Fig. 5). Samples inoculated with $P$. phosphoreum and $C$. maltaromaticum were quickly strongly spoiled and presented the same spoilage behaviour as $P$. phosphoreum single-species samples (Fig. 3). Sour, amine and acid odours were also characteristic of these samples (Fig. $4 \mathrm{~A}$ ).

The bacterial concentration of $C$. maltaromaticumin co-culture with $H$. alvei was similar to that previously described for the single species. However, $H$. alvei growth was slightly inhibited and reached about $7.2 \mathrm{Log}\left(\mathrm{CFU} . \mathrm{g}^{-1}\right)$ in the presence of $C$. maltaromaticum (Fig. 2 B). C. maltaromaticum and $H$. alvei co-culture inoculated products did not exceed $32 \mathrm{mg}-\mathrm{N}$ TVBN $100 \mathrm{~g}^{-1}$ and $10 \mathrm{mg}-\mathrm{N}$ TMA $100 \mathrm{~g}^{-1}$ (Fig. 5). These samples presented the same spoilage kinetics as $C$. maltaromaticum alone and the same characteristic odours of butter and feet/cheese at the end of storage (Figs. 3 and 4 B).

TTGE analysis enabled visualization of microbiota dynamics by examining fingerprints of the dominant bacterial groups evolving during storage (Fig. 6) in co-culture inoculated samples. In order to analyse the TTGE patterns, fingerprints of the different samples were compared with those of pure isolates involved in each bacterial group: C. maltaromaticum, $\mathrm{H}$. alvei, and $P$. phosphoreum. In fact, these species are present in different seafood products and some of them have already been studied by PCR-TTGE in our laboratory (Macé et al., 2012).Concerning $P$. phosphoreum and $H$. alvei, several pure isolates were used for assignation because their TTGE profiles present several different bands.

No strain patterns were visualized in any of the samples after 1 day of storage (data not shown). C. maltaromaticum and $P$. phosphoreum co-culture TTGE patterns are shown in Fig. 6 A. By comparing band migration positions, C. maltaromaticum was assigned 3 salmon 
samples after 6,8 and 11 days of storage. P. phosphoreum typical bands were visualized in 4 samples, from 4 days until the end of storage. In $C$. maltaromaticum and $H$. alvei co-culture samples (Fig. 6 B), the $C$. maltaromaticumband was assigned to the samples from 4 to 11 days. Weak bands corresponding to $H$. alvei patterns could be observed in samples D6, D8 and D11.

\section{Discussion}

In this study, we determined the spoilage potential of eight bacterial groups previously isolated from naturally contaminated spoiled salmon batches and inoculated onto an ionized raw salmon matrix. A mix of at least 2 strains per species was used in most cases to avoid a strain effect that which is commonly described for spoilage bacteria (Stohr et al., 2001; Joffraud et al., 2006; Laursen et al., 2006).

In the preliminary characterization of spoilage potential, only five bacterial groups of the eight tested were considered strong spoilers after 11 days of storage at $8^{\circ} \mathrm{C}$ : C. maltaromaticum, B. thermosphacta, P. phosphoreum, H. alvei and "other Enterobacteriaceae". All bacterial isolates present on naturally contaminated spoiled salmon are not involved in spoilage, which is in accordance with the SSO concept (Dalgaard, 2000; Gram and Dalgaard, 2002).

For each 3 single-species group tested in further characterisation step, spoilage of the inoculated sample started after the exponential stage and at the beginning of the stationary phase of growth in accordance with typical SSO behaviour (Gram and Huss, 1996; Dalgaard, 2000; Gram and Dalgaard, 2002). This was observed after 4 days for $P$. phosphoreum, 8 days for $C$. maltaromaticum and 11 days for $H$. alvei,respectively.

According again to SSO concept, bacterial growth should be about 6 or 7 Log $\left(C F U . g^{-1}\right)$ to allow enough spoilage metabolite production. However, despite its weak growth after 7 days of storage (4 Log (CFU.g ${ }^{-1}$ ) presented in Fig. 1, P. phosphoreum appeared very spoiling. This could be explained following a more precise monitoring of $P$. phosphoreum growth during the further characterization of spoilage potential. In fact, as seen in Fig. 2 A, $P$. phosphoreum presented a very fast growth on the matrix and then a decline at about 8 days of storage (both in mono- and in co-culture). This typical growth behaviour may have occurred during the preliminary characterization of spoilage potential: $P$. phosphoreum could have reached a sufficient growth to spoil the product between days 3 and 7 . Moreover, the low bacterial count obtained at day 7 (Fig. 1) was probably observed during the growth decline.

P. phosphoreum has been identified as an SSO responsible for trimethylamine (TMA) production and spoilage of marine fish (Dalgaard et al., 1993; Dalgaard, 1995; Dalgaard et al., 1997; Hovda et al., 2007; Reynisson et al., 2009) and notably of raw salmon (Emborg et al., 2002; Hansen et al., 2009). This was confirmed in this work.P. phosphoreum inoculated samples presented amine and sour off-odours, also described for naturally contaminated spoiled salmon under MAP (Emborg et al., 2002; Hansen et al., 2009; Macé et al., 2012). Moreover, we have also underlined the strong spoilage potential of some Enterobacteriaceae like $H$. alvei and other isolates of the "other Enterobacteriaceae" group. These bacterial groups were already known as cold-smoked salmon spoilers (Jorgensen et al., 2000; Joffraud et al., 2001) and also as a biogenic amine producer in cold-smoked salmon for $H$. alvei(Jorgensen et al., 2000) but, to our knowledge, their spoilage abilities have never been demonstrated in raw salmon.Pyrrolidine odours with slightly sour odours were noticed on $H$. alveinnoculated samples and mixed species group "other Enterobacteriaceae" produced a typical cabbage odour. 
C. maltaromaticum and $B$. thermosphacta are known as dominant bacteria in raw salmon (de la Hoz et al., 2000; Rudi et al., 2004) and present spoilage ability on several seafood and meat products (Mejlholm et al., 2005; Vermeiren et al., 2005; Laursen et al., 2006; Afzal et al., 2010; Jaffrès et al., 2011). C. maltaromaticum samples also presented butter and feet/cheese off-odours Feet/cheese and/or butter odour were also noticed for this species during shrimp and cold-smoked salmon spoilage (Joffraud et al., 2001; Jaffrès et al., 2011). $B$. thermosphacta samples were characterised by a sour odour like it has already been demonstrated for inoculated shrimp samples (Jaffrès et al., 2011)

Although S. baltica and Serratiaspp. belong to two genera well known for their spoilage ability on other products like, respectively, fresh fish (Gram and Dalgaard, 2002), coldsmoked salmon (Stohr et al., 2001), shrimp (Jaffrès et al., 2011) or meat products (Borch et al., 1996; Ercolini et al., 2009; Schirmer and Langsrud, 2010; Doulgeraki et al., 2011), here they were considered moderate spoilers.Acid odour combined with a mix of spoilage odours like sour, feet/cheese and amines were found in $S$. baltica inoculated samples and pyrrolidine odours in Serratia samples. It can be noticed that pyrrolidine odour should be characteristic of some Enterobacteriaceaebecause it has been produced by Serratia spp. and $H$. alvei.

The L. piscium group, producing butter odours like the other LAB tested here $C$. maltaromaticum, was here considered as low spoilers in accordance with several studies on seafood (Matamoros et al., 2009; Fall et al., 2012). However, in a recent study, L. piscium isolates were involved in meat spoilage (Rahkila et al., 2012). These results confirm the fact that spoilage potential is dependent on the bacterial species, strain and food matrix (Stohr et al., 2001; Joffraud et al., 2006; Laursen et al., 2006).

Among the five spoiler bacterial groups, three were considered stronger regarding their speed of spoilage: $P$. phosphoreum, $C$. maltaromaticum and $H$. alvei. Their spoilage potential was thus studied alone or in combination using a multi-parameter approach to investigate any interaction between species in terms of growth, chemical changes and sensory evolution. This type of approach has already been used in several works on cold-smoked salmon (Truelstrup Hansen, 1995; Jorgensen et al., 2000; Joffraud et al., 2006).

Growth differences were found between bacteria in co-culture or alone in the matrix. $C$. maltaromaticumseemed to be slightly inhibited by the presence of $P$. phosphoreum with a decrease of about $1 \mathrm{Log}\left(\mathrm{CFU} \cdot \mathrm{g}^{-1}\right)$. TTGE analyses were used to visualize the dominant group evolution during storage and confirmed the bacterial count results (Fig. 6). $P$. phosphoreum bands were observed earlier than C. maltaromaticum profiles on the matrix (from day 4), confirming its dominance. In contrast, in previous studies dealing with coinoculation challenges on cold-smoked salmon, $P$. phosphoreum was weakly inhibited by $C$. piscicola or C. divergens(Jorgensen et al., 2000; Joffraud et al., 2006).

In the presence of $H$. alvei, $C$. maltaromaticum was not inhibited; no difference in count level was observed alone or in co-culture. In this case, $\mathrm{H}$. alvei exhibited a lower growth in the presence of $C$. maltaromaticum. Inhibition of $H$. alvei strains by LAB, notably $C$. divergens, has already been demonstrated (Jorgensen et al., 2000). Concerning TTGE analysis, C. maltaromaticum dominated the samples during storage with intense bands visible from day 4 to the end. Very weak bands assigned to $H$. alvei were observed from day 6 and confirmed the bacterial count results obtained previously.

This study highlights the interaction between major spoilage microorganisms of raw salmon samples. Several types of bacterial interaction may be involved, such as antagonism or metabiosis. Antagonistic interaction during spoilage has been shown in a number of studies and several ways can be used to inhibit microorganisms, such as bacteriocin production (Metaxopoulos et al., 2002), competition for nutrients (Gram and Melchiorsen, 1996) or 
changes in environmental conditions ( $\mathrm{pH}$ decrease due to organic acid production) (Malakar et al., 1999; Russo et al., 2006). In our experiments, microorganism growth also resulted in a limited $\mathrm{pH}$ decrease. Once again, each single group inoculated sample presented a different $\mathrm{pH}$ fall while for co-culture samples the dominant group imposed its behaviour. $C$. maltaromaticum presented the largest drop in $\mathrm{pH}(0.4$ units) among the species tested but this acidification is not sufficient to play a role in the inhibition of $H$. alvei. It is also important to mention that no clear Jameson effect was observed for any of the bacteria in this work, contrary to what has been described in several other studies, in particular when lactic acid bacteria are present (Ross et al., 2000; Giménez and Dalgaard, 2004; Fall et al., 2010).

We demonstrated here that growth inhibition is co-culture dependent. In fact, $C$. maltaromaticum was an inhibitor in one case (in the presence of $H$. alvei) and inhibited in the other (in co-culture with $P$. phosphoreum).

Our study also shows that the spoilage kinetics and off-odours released from co-culture samples corresponded to those of the dominant species. For example, the samples inoculated with the $P$. phosphoreum and $C$. maltaromaticum co-culture showed the same spoilage behaviour as those with $P$. phosphoreum alone. In both cases, amine and sour odours are present and have already been associated with naturally contaminated MAP spoiled cod (Dalgaard et al., 1993) or spoiled salmon (Emborg et al., 2002; Fletcher et al., 2002; Macé et al., 2012). Amine odours can be linked to P.phosphoreum TMA production which displays amine and ammonia-like odours in several fishes (Dalgaard et al., 1997). Moreover, C. maltaromaticum spoilage kinetics and sensory characteristics were found on the samples inoculated with this species and $H$. alvei. Contrary to (Laursen et al., 2006) study which observed a particular odour formed when C. maltaromaticum and $B$. thermosphacta were co cultured.

TVBN and TMA production were higher in the samples inoculated with both $P$. phosphoreum and C. maltaromaticum, suggesting a stimulation of their production and probably a metabiotic behaviour (Jorgensen et al., 2000; Gram et al., 2002). On the contrary, H. alvei produced the maximum TVBN level at the end of storage when it was alone on the matrix. This concentration was significantly reduced in the samples co-cultured with $C$. maltaromaticum, which could partially be due to the slight growth inhibition of $H$. alveibut probably also to metabolic variations when the two bacterial species are grown together. The modification of bacterial metabolism in co-cultures has been described in several studies as metabiosis and is frequently involved in spoilage mechanisms(Jorgensen et al., 2000; Gram et al., 2002). For example, (Jorgensen et al., 2000) demonstrated that the spoilage activity and biogenic amine production of $H$. alvei was enhanced in the presence of LAB. In vacuumpacked meat, the production of putrescine was enhanced when Enterobacteriaceae were cocultured with some LAB isolates (Dainty et al., 1986).

During the last few years, several studies have shown a correlation between spoilage volatile compound release and the development of specific microbial species during storage of seafood like shrimp (Chinivasagam et al., 1998; Jaffrès et al., 2011), fish (Olafsdottir et al., 2005; Wierda et al., 2006), and cold-smoked salmon (Jonsdottir et al., 2008) and during meat storage (Ercolini et al., 2009; Ercolini et al., 2010; Ercolini et al., 2011).

One of the aims of this study was to investigate the volatile compounds produced by the dominant spoilers, $P$. phosphoreum, to determine spoilage indicators. There are several possible origins for these volatile metabolites and, although it is difficult to attribute them to a specific pathway, some hypotheses can be made. Several volatile compounds have already been described in amino-acid degradation: butanal, 2-methyl; butanal, 3-methyl and 1 propanol-2 methyl. 3-hydroxybutanone is an interesting compound resulting from microorganism glycogen catabolism (Joffraud et al., 2001; Laursen et al., 2006). Ethyl 
acetate and acetic acid are also known to be produced in different metabolic pathways (Joffraud et al., 2001).

3-hydroxybutanone and acetic acid have already been proposed as spoilage markers of Pacific raw salmon (Oncorhynchustshawytscha) (Wierda et al., 2006) and have been detected as compounds contributing to cold-smoked salmon spoilage (Jonsdottir et al., 2008). Moreover, an increase in 3-hydroxybutanone during spoilage has been described in MAP beef meat (Ercolini et al., 2011) and in spoiled cod fillets where it was related to $P$. phosphoreum growth (Olafsdottir et al., 2005). However, in this study, 3-hydroxybutanone production was very slight and so this compound was not chosen as a marker. The production of acetic acid by $P$. phosphoreum inoculated into salmon juice and cold-smoked salmon block has previously been determined by an enzymatic method (Truelstrup Hansen, 1995). In our study, among all the specific compounds detected, acetic acid is the one that could be linked to a sour odour (Fenaroli, 2001) described for the sample spoiled by $P$. phosphoreum. This suggests that this compound could be an interesting spoilage marker for raw salmon.

Obviously, as it has already been demonstrated, a comparison between volatile compounds and sensory data indicates that it is probably the combination of different compounds rather than a single one which can affect the sensory profile of meat and seafood products (Laursen et al., 2006; Ercolini et al., 2010; Jaffrès et al., 2011). Overall, the P. phosphoreum strain group tested in this study can be considered a spoilage agent of raw salmon through the production of active odour molecules during MAP storage.

\section{Conclusion}

The results of these challenge-test studies show that, within eight bacterial groups associated with raw salmon spoiled fillet stored under MAP, three species were determined as fast and strong spoilers: C. maltaromaticum, $H$. alvei and P.phosphoreum. Their assessment alone or in co-culture, using multi-parametric approach shows that $P$.phosphoreum dominate the spoilage. Indeed $P$. phosphoreum seems to have the highest potential to cause rapid and strong spoilage and to be a raw salmon SSO.All the more, metabolites produce by this bacterium like TMA and acetic acid leads to amine and sour odours which are typical of several naturally spoiled MAP salmon and other fish. Moreover, this work has contributed to characterizing the spoilage potential of bacterial species in association and to underline the interactions between them. Further investigations are needed to understand the mechanism involved in these interactions to have a better comprehension of natural spoilage and, in the future, to develop techniques to reduce product losses.

\section{Acknowledgements}

This study was carried out as part of the MIPROMER program, managed by PôleAgronomiqueOuest (PAO). Sabrina Macé's PhD thesis is financially supported by the Bretagne and Pays de la Loire regions and by Oniris (Nantes). We thank STBM department member Sandrine Bruzac for chemical analyses.The authors are grateful to Prof.LisbethTruelstrup Hansen (Dalhousie University, NS, Canada) for her valuable comments on this manuscript. 


\section{References}

Afzal, M.I., Jacquet, T., Delaunay, S., Borges, F., Milliere, J.B., Revol-Junelles, A.M., CailliezGrimal, C. 2010. Carnobacterium maltaromaticum: identification, isolation tools, ecology and technological aspects in dairy products. Food Microbiology 27, 573-579.

Borch, E., Kant-Muermans, M.-L., Blixt, Y. 1996. Bacterial spoilage of meat and cured meat products. International Journal of Food Microbiology 33, 103-120.

Chinivasagam, H.N., Bremner, H.A., Wood, A.F., Nottingham, S.M. 1998. Volatile components associated with bacterial spoilage of tropical prawns. International Journal of Food Microbiology 42, 45-55.

Conway, E.J., Byrne, A. 1933. An absorption apparatus for the micro-determination of certain volatile substances: The micro-determination of ammonia. Biochemical Journal 27, 419-429.

Dainty, R., Edwards, R.A., Hibbard, C.M., Ramantanis, S.V. 1986. Bacterial source of putrecine and cadaverine in chill stored vacuum-packged beef. Journal of Applied Bacteriology 61.

Dalgaard, P. 1995. Modelling of microbial activity and prediction of shelf life for packed fresh fish. International Journal of Food Microbiology 26, 305-317.

Dalgaard, P. 2000. Fresh and lightly preserved seafood In: Man, C.D., Jones, A.A., (Eds.), Shelf life Evaluation of Foods (2nd edition). Aspen Publishing Inc, Maryland, USA. 110-139.

Dalgaard, P. 2006. Microbiology of marine muscle foods. In: Hui, Y.H., (Ed.), Handbook of Food Science, Technology and Engineering, vol. 1. Taylor \& Francis CRC Press, USA. 53-51 - 53-20.

Dalgaard, P., Gram, L., Huss, H.H. 1993. Spoilage and shelf-life of cod fillets packed in vacuum or modified atmospheres. International Journal of Food Microbiology 19, 283-294.

Dalgaard, P., Mejholm, O., Christiansen, T.J., Huss, H.H. 1997. Importance of Photobacterium phosphoreum in relation to spoilage of modified atmosphere-packed fish products. Letters in Applied Microbiology 24, 373-378.

de la Hoz, L., Lopez-Galvez, D.E., Fernandez, M., Hierro, E., Ordonez, J.A. 2000. Use of carbon dioxide enriched atmospheres in the refrigerated storage (2 degrees $\mathrm{C}$ ) of salmon (Salmo salar) steaks. European Food Research and Technology 210, 179-188.

Doulgeraki, A.I., Paramithiotis, S., Nychas, G.-J.E. 2011. Characterization of the Enterobacteriaceae community that developed during storage of minced beef under aerobic or modified atmosphere packaging conditions. International Journal of Food Microbiology 145, 77-83.

Emborg, J., Laursen, B.G., Rathjen, T., Dalgaard, P. 2002. Microbial spoilage and formation of biogenic amines in fresh and thawed modified atmosphere-packed salmon (Salmo salar) at 2 degrees C. Journal of Applied Microbiology 92, 790-799.

Ercolini, D., Casaburi, A., Nasi, A., Ferrocino, I., Di Monaco, R., Ferranti, P., Mauriello, G., Villani, F. 2010. Different molecular types of Pseudomonas fragi have the same overall behaviour as meat spoilers. International Journal of Food Microbiology 142, 120-131.

Ercolini, D., Ferrocino, I., Nasi, A., Ndagijimana, M., Vernocchi, P., La Storia, A., Laghi, L., Mauriello, G., Guerzoni, M.E., and Villani, F. 2011. Monitoring of microbial metabolites and bacterial diversity in beef stored under different packaging conditions. Applied and Evironmental Microbiology 77, 10.

Ercolini, D., Russo, F., Nasi, A., Ferranti, P., Villani, F. 2009. Mesophilic and psychrotrophic bacteria from meat and their spoilage potential in vitro and in beef. Applied and Evironmental Microbiology 75, 1990-2001.

Fall, P.A., Leroi, F., Cardinal, M., Chevalier, F., Pilet, M.F. 2010. Inhibition of Brochothrix thermosphacta and sensory improvement of tropical peeled cooked shrimp by Lactococcus piscium CNCM I-4031. Letters in Applied Microbiology 50, 357-361.

Fall, P.A., Pilet, M.F., Leduc, F., Cardinal, M., Duflos, G., Guérin, C., Joffraud, J.-J., Leroi, F. 2012. Sensory and physicochemical evolution of tropical cooked peeled shrimp inoculated by Brochothrix thermosphacta and Lactococcus piscium CNCM I-4031 during storage at $8^{\circ} \mathrm{C}$. International Journal of Food Microbiology 152, 82-90. 
Fenaroli. 2001. Fenaroli's Handbook of Flavor Ingredients 4th Edition. CRC Press, Orlando, Florida, USA ed.

Fletcher, G.C., Summers, G., Corrigan, V., Cumarasamy, S., Dufour, J.P. 2002. Spoilage of king salmon (Oncorhynchus tshawytscha) fillets stored under different atmospheres. Journal of Food Science 67, 2362-2374.

Giménez, B., Dalgaard, P. 2004. Modelling and predicting the simultaneous growth of Listeria monocytogenes and spoilage micro-organisms in cold-smoked salmon. Journal of Applied Microbiology 96, 96-109.

Gram, L., Dalgaard, P. 2002. Fish spoilage bacteria--problems and solutions. Current Opinion Biotechnology 13, 262-266.

Gram, L., Huss, H.H. 1996. Microbiological spoilage of fish and fish products. International Journal of Food Microbiology 33, 121-137.

Gram, L., Melchiorsen, J. 1996. Interaction between fish spoilage bacteria Pseudomonas sp. and Shewanella putrefaciens in fish extracts and on fish tissue. Journal of Applied Microbiology 80, 589-595.

Gram, L., Ravn, L., Rasch, M., Bruhn, J.B., Christensen, A.B., Givskov, M. 2002. Food spoilage - interactions between food spoilage bacteria. International Journal of Food Microbiology 78, 79-97.

Hansen, A.A., Morkore, T., Rudi, K., Rodbotten, M., Bjerke, F., Eie, T. 2009. Quality changes of prerigor filleted Atlantic salmon (Salmo salar L.) packaged in modified atmosphere using $\mathrm{CO}_{2}$ emitter, traditional MAP, and vacuum. Journal of Food Science 74, M242-M249.

Hovda, M.B., Sivertsvik, M., Lunestad, B.T., Lorentzen, G., Rosnes, J.T. 2007. Characterisation of the dominant bacterial population in modified atmosphere packaged farmed halibut (Hippoglossus hippoglossus) based on 16S rDNA-DGGE. Food Microbiology 24, 362-371.

Jaffrès, E., Lalanne, V., Macé, S., Cornet, J., Cardinal, M., Sérot, T., Dousset, X., Joffraud, J.J. 2011. Sensory characteristics of spoilage and volatile compounds associated with bacteria isolated from cooked and peeled tropical shrimps using SPME-GC-MS analysis. International Journal of Food Microbiology 147, 195-202.

Jaffrès, E., Sohier, D., Leroi, F., Pilet, M.F., Prévost, H., Joffraud, J.J., Dousset, X. 2009. Study of the bacterial ecosystem in tropical cooked and peeled shrimps using a polyphasic approach. International Journal of Food Microbiology 131, 20-29.

Joffraud, J.J., Cardinal, M., Cornet, J., Chasles, J.S., Leon, S., Gigout, F., Leroi, F. 2006. Effect of bacterial interactions on the spoilage of cold-smoked salmon. International Journal of Food Microbiology 112, 51-61.

Joffraud, J.J., Leroi, F., Roy, C., BerdaguÃ®, J.L. 2001. Characterisation of volatile compounds produced by bacteria isolated from the spoilage flora of cold-smoked salmon. International Journal of Food Microbiology 66, 175-184.

Joffraud, J.J., Leroi, F., Chevalier, F. 1998. Development of a sterile cold-smoked fish model. Journal of Applied Microbiology 85, 991-998.

Jonsdottir, R., Olafsdottir, G., Chanie, E., Haugen, J.-E. 2008. Volatile compounds suitable for rapid detection as quality indicators of cold smoked salmon (Salmo salar). Food Chemistry 109, 184-195.

Jorgensen, L.V., Huss, H.H., Dalgaard, P. 2000. The effect of biogenic amine producton by single bacterial cultures and metabiosis on cold salmon. Journal of Applied Microbiology 89, 920-934.

Laursen, B.G., Leisner, J.J., Dalgaard, P. 2006. Carnobacterium species: effect of metabolic activity and interaction with Brochothrix thermosphacta on sensory characteristics of modified atmosphere packed shrimp. Journal of Agricultural and Food Chemistry 54, 3604-3611.

Macé, S., Cornet, J., Chevalier, F., Cardinal, M., Pilet, M.-F., Dousset, X., Joffraud, J.-J. 2012. Characterisation of the spoilage microbiota in raw salmon (Salmo salar) steaks stored under vacuum or modified atmosphere packaging combining conventional methods and PCR-TTGE. Food Microbiology 30, 164-172. 
Malakar, P.K., Martens, D.E., Zwietering, M.H., Béal, C., van 't Riet, K. 1999. Modelling the interactions between Lactobacillus curvatus and Enterobacter cloacae: II. Mixed cultures and shelf life predictions. International Journal of Food Microbiology 51, 67-79.

Matamoros, S., Leroi, F., Cardinal, M., Gigout, F., Kasbi Chadli, F., Cornet, J., Prevost, H., Pilet, M.F. 2009. Psychrotrophic lactic acid bacteria used to improve the safety and quality of vacuum-packaged cooked and peeled tropical shrimp and cold-smoked salmon. Journal of Food Protection 72, 365-374.

Mejlholm, O., Bøknæs, N., Dalgaard, P. 2005. Shelf life and safety aspects of chilled cooked and peeled shrimps (Pandalus borealis) in modified atmosphere packaging. Journal of Applied Microbiology 99, 66-76.

Metaxopoulos, J., Mataragas, M., Drosinos, E.H. 2002. Microbial interaction in cooked cured meat products under vacuum or modified atmosphere at $4^{\circ} \mathrm{C}$. Journal of Applied Microbiology 93, 363-373.

Olafsdottir, G., Jonsdottir, R., Lauzon, H.L., Luten, J., Kristbergsson, K. 2005. Characterization of volatile compounds in chilled cod (Gadus morhua) fillets by gas chromatography and detection of quality indicators by an electronic nose. Journal of Agricultural Food Chemistry 53, 10140-10147.

Powell, S.M., Tamplin, M.L. 2012. Microbial communities on Australian modified atmosphere packaged Atlantic salmon. Food Microbiology 30, 226-232.

Rahkila, R., Nieminen, T., Johansson, P., Säde, E., Björkroth, J. 2012. Characterization and evaluation of the spoilage potential of Lactococcus piscium isolates from modified atmosphere packaged meat. International Journal of Food Microbiology 156, 50-59.

Reynisson, E., Lauzon, H.L., Magnusson, H., Jonsdottir, R., Olafsdottir, G., Marteinsson, V., Hreggvidsson, G.O. 2009. Bacterial composition and succession during storage of NorthAtlantic cod (Gadus morhua) at superchilled temperatures. BMC Microbiol 9, 250.

Ross, T., Dalgaard, P., Tienungoon, S. 2000. Predictive modelling of the growth and survival of Listeria in fishery products. International Journal of Food Microbiology 62, 231-245.

Rudi, K., Maugesten, T., Hannevik, S.E., Nissen, H. 2004. Explorative multivariate analyses of 16S rRNA gene data from microbial communities in modified-atmosphere-packed salmon and coalfish. Applied and Environmental Microbiology 70, 5010-5018.

Russo, F., Ercolini, D., Mauriello, G., Villani, F. 2006. Behaviour of Brochothrix thermosphacta in presence of other meat spoilage microbial groups. Food Microbiology 23, 797-802.

Schirmer, B.C., Heiberg, R., Eie, T., Moretro, T., Maugesten, T., Carlehog, M., Langsrud, S. 2009. A novel packaging method with a dissolving $\mathrm{CO}_{2}$ headspace combined with organic acids prolongs the shelf life of fresh salmon. International Journal of Food Microbiology 133, 154-160.

Schirmer, B.C., Langsrud, S. 2010. Evaluation of natural antimicrobials on typical meat spoilage bacteria in vitro and in vacuum-packed pork meat. Journal of Food Science 75, M98-M102.

Sivertsvik, M., Jeksrud, J., Rosnes, J.T. 2002. A review of modified atmosphere packaging of fish and fishery products - significance of microbial growth, activities and safety. International Journal of Food Science and Technology 37, 107-127.

Sivertsvik, M., Rosnes, J.T., Kleiberg, G.H. 2003. Effect of modified atmosphere packaging and superchilled storage on the microbial and sensory quality of Atlantic salmon (Salmo salar) fillets. Journal of Food Science 68, 1467-1472.

Stohr, V., Joffraud, J.J., Cardinal, M., Leroi, F. 2001. Spoilage potential and sensory profile associated with bacteria isolated from cold-smoked salmon. Food Research International 34, 797-806.

Stone, H., Sidel, J.L. 2004. Sensory evaluation practices 3rd edition Elsevier Academic Press, Amsterdam.

Truelstrup Hansen, L. 1995. Quality of chilled, vacuum packed cold-smoked salmon, Danish Institute of Fisheries Research and Royal Veterinary and Agricultural University, Copenhague, Denmark. 
Vermeiren, L., Devlieghere, F., De Graef, V., Debevere, J. 2005. In vitro and in situ growth characteristics and behaviour of spoilage organisms associated with anaerobically stored cooked meat products. Journal of Applied Microbiology 98, 33-42.

Wierda, R.L., Fletcher, G., Xu, L., Dufour, J.P. 2006. Analysis of volatile compounds as spoilage indicators in fresh king salmon (Oncorhynchus tshawytscha) during storage using SPME-GC-MS. Journal of Agricultural and Food Chemistry 54, 8480-8490. 
Tables

Table 1. List of bacterial isolates inoculated on sterile salmon cubes during challenge tests

\begin{tabular}{|c|c|c|c|}
\hline Bacterial Identity/Group & $\begin{array}{l}\text { Ifremer/Oniris Strain } \\
\text { Library Code }\end{array}$ & Species & Strain Origin \\
\hline \multirow{4}{*}{ Lactococcus piscium } & MIP 2434 & L. piscium & Spoiled salmon batch A \\
\hline & MIP 2450 & L. piscium & Spoiled salmon batch B \\
\hline & MIP 2482 & L. piscium & Spoiled salmon batch C \\
\hline & MIP 2484 & L. piscium & Spoiled salmon batch C \\
\hline \multirow{3}{*}{$\begin{array}{l}\text { Carnobacterium } \\
\text { maltaromaticum }\end{array}$} & MIP 2427 & C. maltaromaticum & Spoiled salmon batch A \\
\hline & MIP 2452 & C. maltaromaticum & Spoiled salmon batch B \\
\hline & MIP 2415 & C. maltaromaticum & Other spoiled salmon sample \\
\hline \multirow{4}{*}{$\begin{array}{l}\text { Brochothrix } \\
\text { thermosphacta }\end{array}$} & MIP 2440 & B. thermosphacta & Spoiled salmon batch A \\
\hline & MIP 2441 & B. thermosphacta & Spoiled salmon batch A \\
\hline & MIP 2465 & B. thermosphacta & Spoiled salmon batch B \\
\hline & MIP 2489 & B. thermosphacta & Spoiled salmon batch C \\
\hline \multirow{6}{*}{ Hafnia alvei } & MIP 2438 & H. alvei & Spoiled salmon batch A \\
\hline & MIP 2439 & H. alvei & Spoiled salmon batch A \\
\hline & MIP 2461 & H. alvei & Spoiled salmon batch B \\
\hline & MIP 2467 & H. alvei & Spoiled salmon batch B \\
\hline & MIP 2468 & H. alvei & Spoiled salmon batch B \\
\hline & MIP 2483 & H. alvei & Spoiled salmon batch $\mathrm{C}$ \\
\hline \multirow{3}{*}{ Serratia spp. } & MIP 2492 & Serratia sp. & Spoiled salmon batch $\mathrm{C}$ \\
\hline & MIP 2425 & S. proteamaculans & Spoiled salmon batch A \\
\hline & MIP 2493 & S. proteamaculans & Spoiled salmon batch C \\
\hline \multirow{3}{*}{$\begin{array}{c}\text { "Other } \\
\text { Enterobacteriaceae" }\end{array}$} & MIP 2451 & Moellerella sp. & Spoiled salmon batch $\mathrm{C}$ \\
\hline & MIP 2488 & Morganella sp. & Spoiled salmon batch C \\
\hline & MIP 2433 & Pectobacterium sp. & Spoiled salmon batch A \\
\hline \multirow{4}{*}{$\begin{array}{l}\text { Photobacterium } \\
\text { phosphoreum }\end{array}$} & MIP 2423 & P. phosphoreum & Spoiled salmon batch A \\
\hline & MIP 2472 & P. phosphoreum & Spoiled salmon batch C \\
\hline & MIP 2473 & P. phosphoreum & Spoiled salmon batch C \\
\hline & MIP 2478 & P. phosphoreum & Spoiled salmon batch C \\
\hline \multirow{2}{*}{ Shewanella baltica } & MIP 2418 & S. baltica & Other spoiled salmon sample \\
\hline & MIP 2486 & S. baltica & Spoiled salmon batch C \\
\hline
\end{tabular}


Table 2. Spoilage level of raw salmon cubes inoculated with 8 bacterial groups followed by storage under MAP at $8^{\circ} \mathrm{C}$ for 12 days

${ }^{1}$ Percentage of panellists who assigned this sensory category to the sample

1 day $\quad 7$ days 12 days

\begin{tabular}{|c|c|c|c|c|c|c|c|c|c|}
\hline Inoculated Bacterial Groups & $\begin{array}{c}\text { Non- } \\
\text { spoiled }\end{array}$ & $\begin{array}{l}\text { Lightly } \\
\text { spoiled }\end{array}$ & $\begin{array}{c}\text { Strongly } \\
\text { spoiled }\end{array}$ & $\begin{array}{c}\text { Non- } \\
\text { spoiled }\end{array}$ & $\begin{array}{l}\text { Lightly } \\
\text { spoiled }\end{array}$ & $\begin{array}{l}\text { Strongly } \\
\text { spoiled }\end{array}$ & $\begin{array}{l}\text { Non- } \\
\text { spoiled }\end{array}$ & $\begin{array}{l}\text { Lightly } \\
\text { spoiled }\end{array}$ & $\begin{array}{r}\text { Strongly } \\
\text { spoiled }\end{array}$ \\
\hline Non-inoculated control & $77.8^{1}$ & 22.2 & 0 & 66.7 & 22.2 & 11.1 & 22.2 & 77.8 & 0 \\
\hline Lactococcus piscium & 44.4 & 55.6 & 0 & 11.1 & 66.7 & 22.2 & 55.6 & 44.4 & 0 \\
\hline $\begin{array}{l}\text { Carnobacterium } \\
\text { maltaromaticum }\end{array}$ & 77.8 & 22.2 & 0 & 0 & 0 & 100 & 0 & 44.4 & 55.6 \\
\hline Brochothrix thermosphacta & 77.8 & 22.2 & 0 & 22.2 & 77.8 & 0 & 0 & 0 & 100 \\
\hline Hafnia alvei & 77.8 & 22.2 & 0 & 0 & 33.3 & 66.7 & 0 & 11.1 & 88.9 \\
\hline Serratia spp. & 88.9 & 11.1 & 0 & 11.1 & 44.4 & 44.4 & 0 & 55.6 & 44.4 \\
\hline "Other Enterobacteriaceae" & 77.8 & 22.2 & 0 & 0 & 55.6 & 44.4 & 0 & 0 & 100 \\
\hline Photobacterium phosphoreum & 66.7 & 33.3 & 0 & 0 & 0 & 100 & 0 & 0 & 100 \\
\hline Shewanella baltica & 88.9 & 11.1 & 0 & 22.2 & 33.3 & 44.4 & 11.1 & 55.6 & 33.3 \\
\hline
\end{tabular}


Table 3. Main odours in salmon matrix inoculated with 8 bacterial groups followed by storage under MAP at $8^{\circ} \mathrm{C}$ for 12 days Frequency of judges $(n=9)$ noting specific odour characteristics are indicated in brackets Mains odours presented are as noted by at least 3 panellists

\begin{tabular}{|c|c|c|c|c|c|c|c|c|c|}
\hline & $\begin{array}{c}\text { Non- } \\
\text { inoculated } \\
\text { control }\end{array}$ & $\begin{array}{l}\text { Lactococcus } \\
\text { piscium }\end{array}$ & $\begin{array}{l}\text { Carnobacterium } \\
\text { maltaromaticum }\end{array}$ & $\begin{array}{l}\text { Brochothrix } \\
\text { thermosphacta }\end{array}$ & Hafnia alvei & $\begin{array}{l}\text { Serratia } \\
\text { spp. }\end{array}$ & $\begin{array}{c}\text { "Other } \\
\text { Enterobacteriaceae } \\
\text { " }\end{array}$ & $\begin{array}{c}\text { Photobacterium } \\
\text { phosphoreum }\end{array}$ & $\begin{array}{l}\text { Shewanella } \\
\text { baltica }\end{array}$ \\
\hline \multirow{3}{*}{ Day 7} & $\begin{array}{l}\text { Nothing } \\
(88.9 \%)\end{array}$ & $\begin{array}{c}\text { Butter } \\
(77.8 \%)\end{array}$ & $\begin{array}{l}\text { Butter } \\
(55.6 \%)\end{array}$ & $\begin{array}{l}\text { Nothing } \\
(55.6 \%)\end{array}$ & $\begin{array}{l}\text { Pyrrolidine } \\
(77.8 \%)\end{array}$ & $\begin{array}{l}\text { Pyrrolidine } \\
\quad(77.8 \%)\end{array}$ & $\begin{array}{c}\text { Sour } \\
(44.4 \%)\end{array}$ & $\begin{array}{c}\text { Sour } \\
(88.9 \%)\end{array}$ & $\begin{array}{l}\text { Amine } \\
(33.3 \%)\end{array}$ \\
\hline & $\begin{array}{l}\text { Fatty fish } \\
(44.4 \%)\end{array}$ & $\begin{array}{l}\text { Fatty fish } \\
(55.6 \%)\end{array}$ & $\begin{array}{c}\text { Feet/Cheese } \\
(44.4 \%)\end{array}$ & $\begin{array}{c}\text { Sour } \\
(44.4 \%)\end{array}$ & $\begin{array}{l}\text { Nothing } \\
(55.6 \%)\end{array}$ & $\begin{array}{l}\text { Nothing } \\
(55.6 \%)\end{array}$ & $\begin{array}{c}\text { Pyrrolidine } \\
(55.6 . \%)\end{array}$ & $\begin{array}{l}\text { Amine } \\
(66.7 \%)\end{array}$ & \\
\hline & & & & & & & $\begin{array}{l}\text { Nothing } \\
(44.4 \%)\end{array}$ & & \\
\hline \multirow{4}{*}{ Day 12} & $\begin{array}{l}\text { Nothing } \\
(44.4 \%)\end{array}$ & $\begin{array}{l}\text { Nothing } \\
(44.4 \%)\end{array}$ & $\begin{array}{c}\text { Sour } \\
(77.8 \%)\end{array}$ & $\begin{array}{c}\text { Sour } \\
(66.7 \%)\end{array}$ & $\begin{array}{l}\text { Pyrrolidine } \\
(55.6 \%)\end{array}$ & $\begin{array}{l}\text { Pyrrolidine } \\
(55.6 \%)\end{array}$ & $\begin{array}{l}\text { Cabbage } \\
(66.7 \%)\end{array}$ & $\begin{array}{l}\text { Amine } \\
(77.8 \%)\end{array}$ & $\begin{array}{c}\text { Acid } \\
(44.4 \%)\end{array}$ \\
\hline & $\begin{array}{l}\text { Butter } \\
(33.3 \%)\end{array}$ & $\begin{array}{l}\text { Fatty fish } \\
(33.3 \%)\end{array}$ & $\begin{array}{c}\text { Feet/Cheese } \\
(33.3 \%)\end{array}$ & $\begin{array}{l}\text { Amine } \\
(44.4 \%)\end{array}$ & $\begin{array}{c}\text { Sour } \\
(44.4 \%)\end{array}$ & $\begin{array}{l}\text { Nothing } \\
(44.4 \%)\end{array}$ & $\begin{array}{c}\text { Feet/Cheese } \\
(33.3 \%)\end{array}$ & $\begin{array}{c}\text { Sour } \\
(66.7 \%)\end{array}$ & $\begin{array}{l}\text { Sour } \\
(33.3 \%)\end{array}$ \\
\hline & & & & Butter $(33.3 \%)$ & & & & & $\begin{array}{c}\text { Feet/Chees } \\
\quad(33.3 \%)\end{array}$ \\
\hline & & & & $\begin{array}{c}\text { Feet/Cheese } \\
(33.3 \%)\end{array}$ & & & & & $\begin{array}{l}\text { Amine } \\
(33.3 \%)\end{array}$ \\
\hline
\end{tabular}


Table 4. Specific volatile compounds identified in non-inoculated and $P$. phosphoreum-inoculated raw salmon matrix after 1 and 8 days of MAP storage at $8^{\circ} \mathrm{C}$

\begin{tabular}{|c|c|c|c|c|}
\hline Volatile Compound & $\begin{array}{l}\text { Non-inoculated } \\
\text { (control) day } 1\end{array}$ & $\begin{array}{c}\text { Non-inoculated } \\
\text { (control) day } 8\end{array}$ & $\begin{array}{c}\text { P. phosphoreum } \\
\text { day } 1\end{array}$ & $\begin{array}{c}\text { P. phosphoreum } \\
\text { day } 8\end{array}$ \\
\hline \multicolumn{5}{|l|}{ Alcohols } \\
\hline Benzene ethanol & ND & ND & ND & $4.48 \pm 0.07^{1}$ \\
\hline 1 propanol-2-methyl & ND & ND & ND & $4.93^{2}$ \\
\hline 3-methyl-2-butanol & ND & ND & ND & $7.03 \pm 0.09$ \\
\hline \multicolumn{5}{|l|}{ Aldehydes } \\
\hline Isobutyraldehyde & ND & ND & ND & $4.56 \pm 0.38$ \\
\hline Butanal, 2-methyl & ND & ND & ND & $5.78 \pm 0.04$ \\
\hline Butanal, 3-methyl & ND & ND & ND & $6.30 \pm 0.05$ \\
\hline Benzaldehyde & ND & ND & ND & $5.39 \pm 0.07$ \\
\hline Benzene acetaldehyde & ND & ND & ND & $6.10 \pm 0.28$ \\
\hline \multicolumn{5}{|l|}{ Acids } \\
\hline Acetic acid & ND & ND & ND & $5.99 \pm 0.51$ \\
\hline \multicolumn{5}{|l|}{ Esters } \\
\hline Ethyl acetate & ND & ND & ND & $6.54 \pm 0.06$ \\
\hline $\begin{array}{c}\text { Ketones } \\
\text { 3-hydroxybutanone }\end{array}$ & $6.01 \pm 0.05$ & $5.77 \pm 0.11$ & $5.89 \pm 0.16$ & $6.32 \pm 0.04$ \\
\hline $\begin{array}{c}\text { Other } \\
\text { Antioxidant BHT }\end{array}$ & $5.44 \pm 0.02$ & $5.46 \pm 0.03$ & $5.40 \pm 0.04$ & $5.31 \pm 0.10$ \\
\hline
\end{tabular}

ND: Not detected

${ }^{1}$ Values are averages \pm standard deviation of $\log$ (peak area/g; $n=3$ )

${ }^{2} \mathrm{n}=1$ 
Figures

Figure1. Growth of eight bacterial groups in raw salmon under MAP during storage at $8^{\circ} \mathrm{C}$.

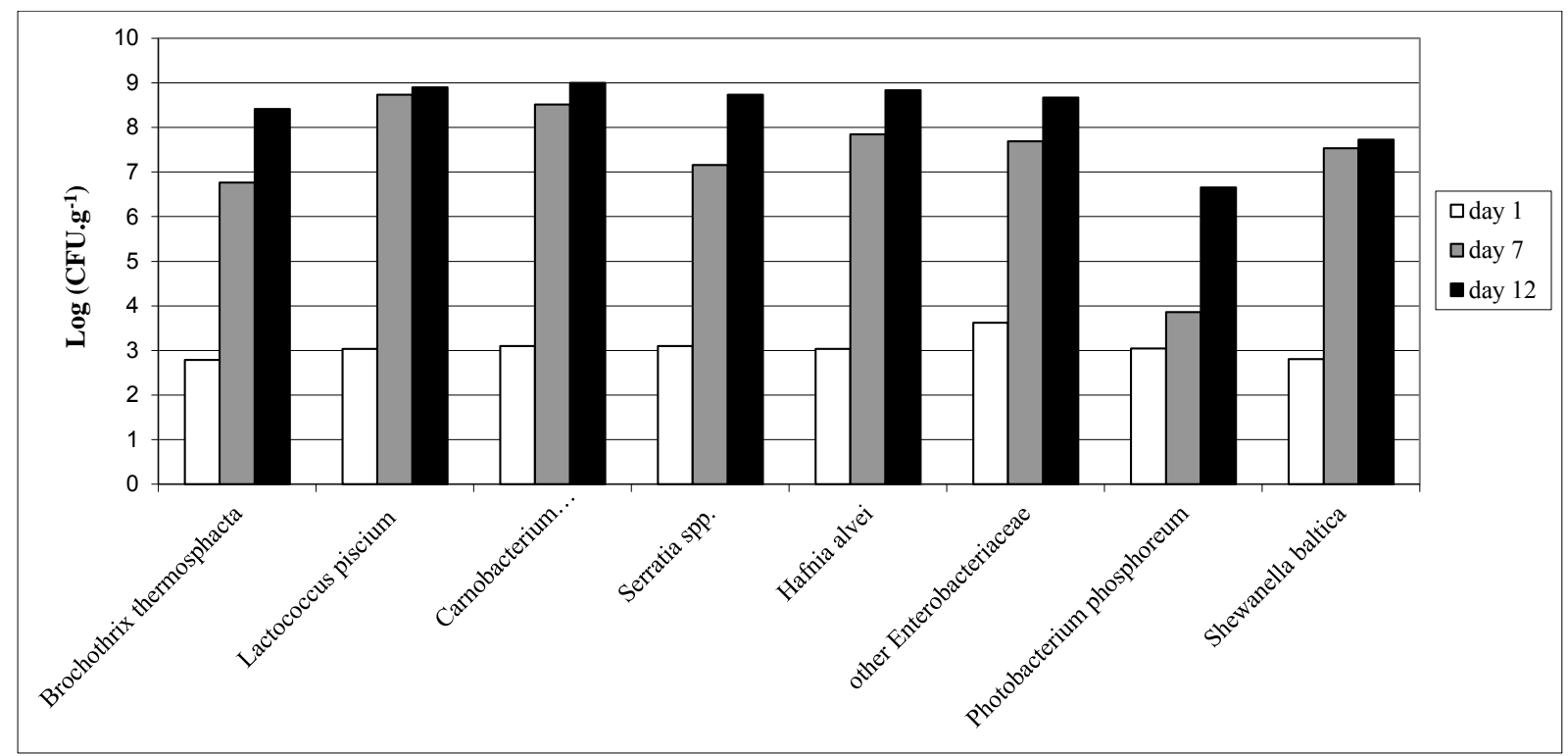

Figure 2. Growth of bacterial groups in raw salmon during MAP storage at $8^{\circ} \mathrm{C}$ : $\mathrm{C}$. maltaromaticum and $P$. phosphoreum group alone or in co-culture $(A)$ and $C$. maltaromaticum and $H$. alvei group alone or in co-culture (B).

Arrows symbols indicate that count values were below the threshold of 0.7 log (CFU.g $\left.{ }^{-1}\right)$

(A)

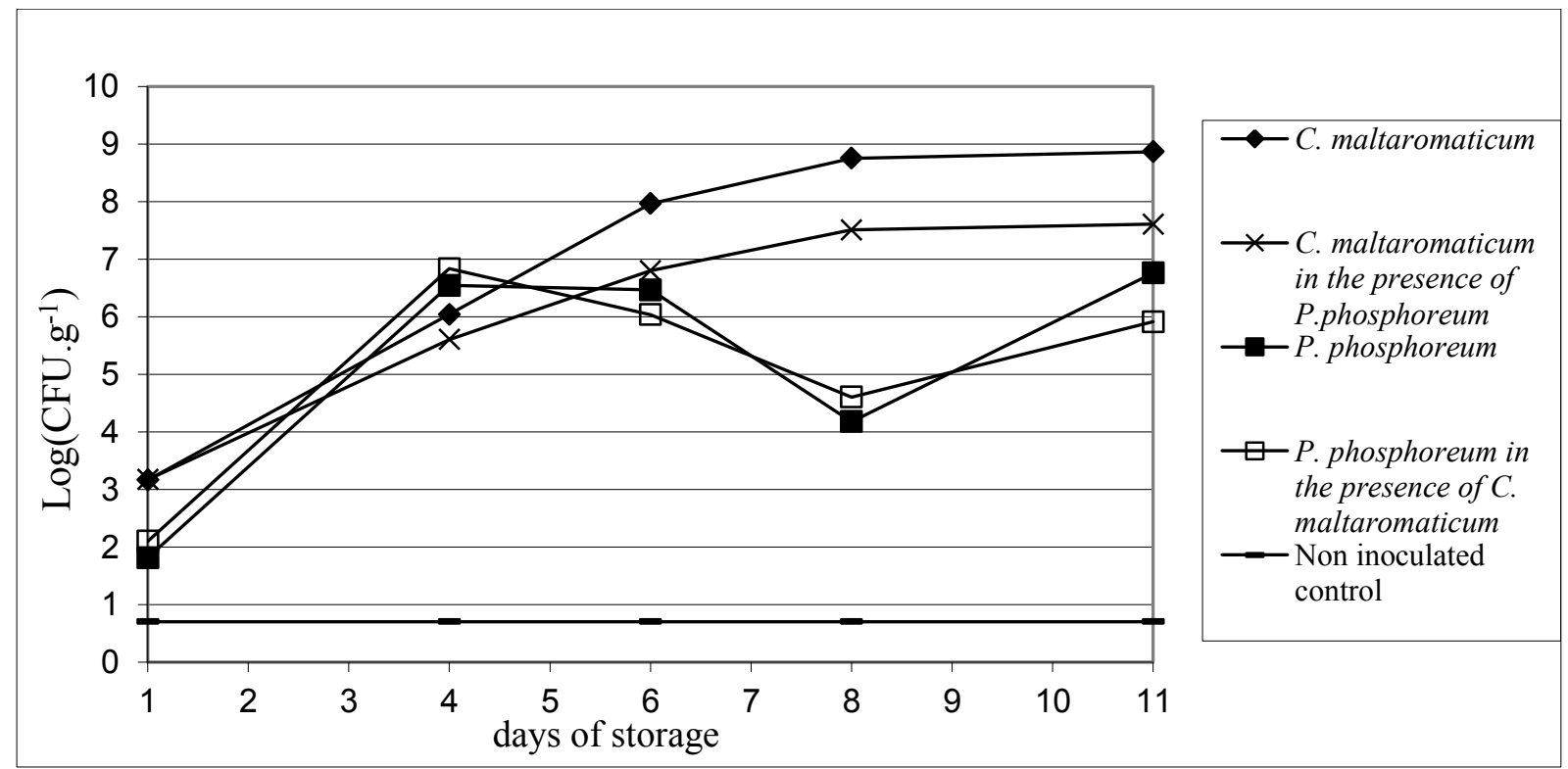


(B)

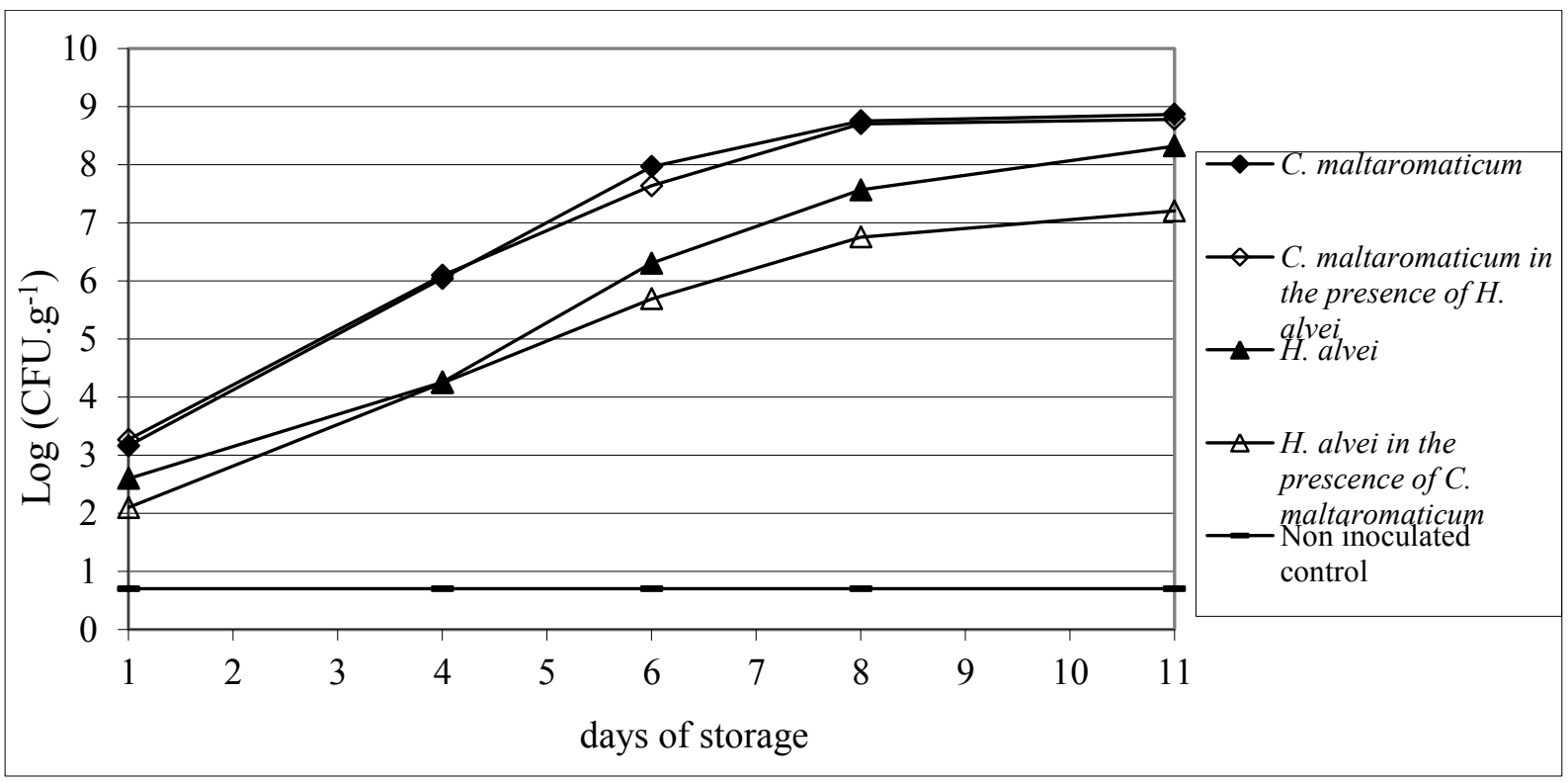

Figure 3. Spoilage level mean scores as determined by the sensory panel (14 panellists) for each of the inoculated salmon samples (continuous scale from 0 to 10). Standard deviation represents difference between panellist responses $(n=14)$.

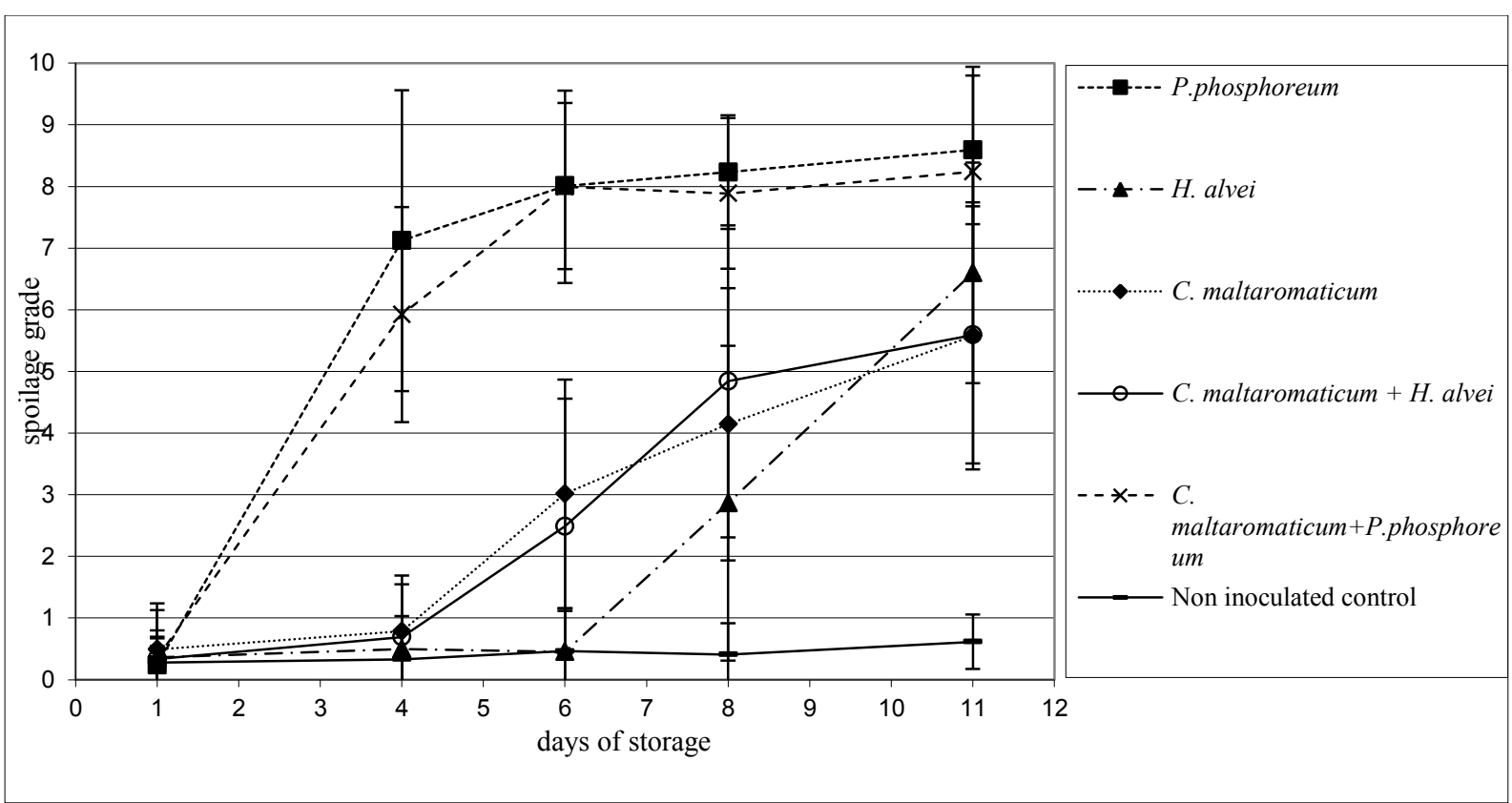


Figure 4. Simultaneous representation of inoculated salmon samples and odour descriptors on planes 1-2 (A) and 1-3 (B) of principal component analysis. Sample nomenclature: C, control samples (non-inoculated); carno, Carnobacterium maltaromaticum; haf, Hafnia alvei; pho, Photobacterium phosphoreum; mpc, co-culture of $P$. phosphoreum and $C$. maltaromaticum; mhc, co-culture of $\mathrm{H}$. alvei and $\mathrm{C}$. maltaromaticum. Numbers in labels of samples represent duration of storage (in days).

(A)

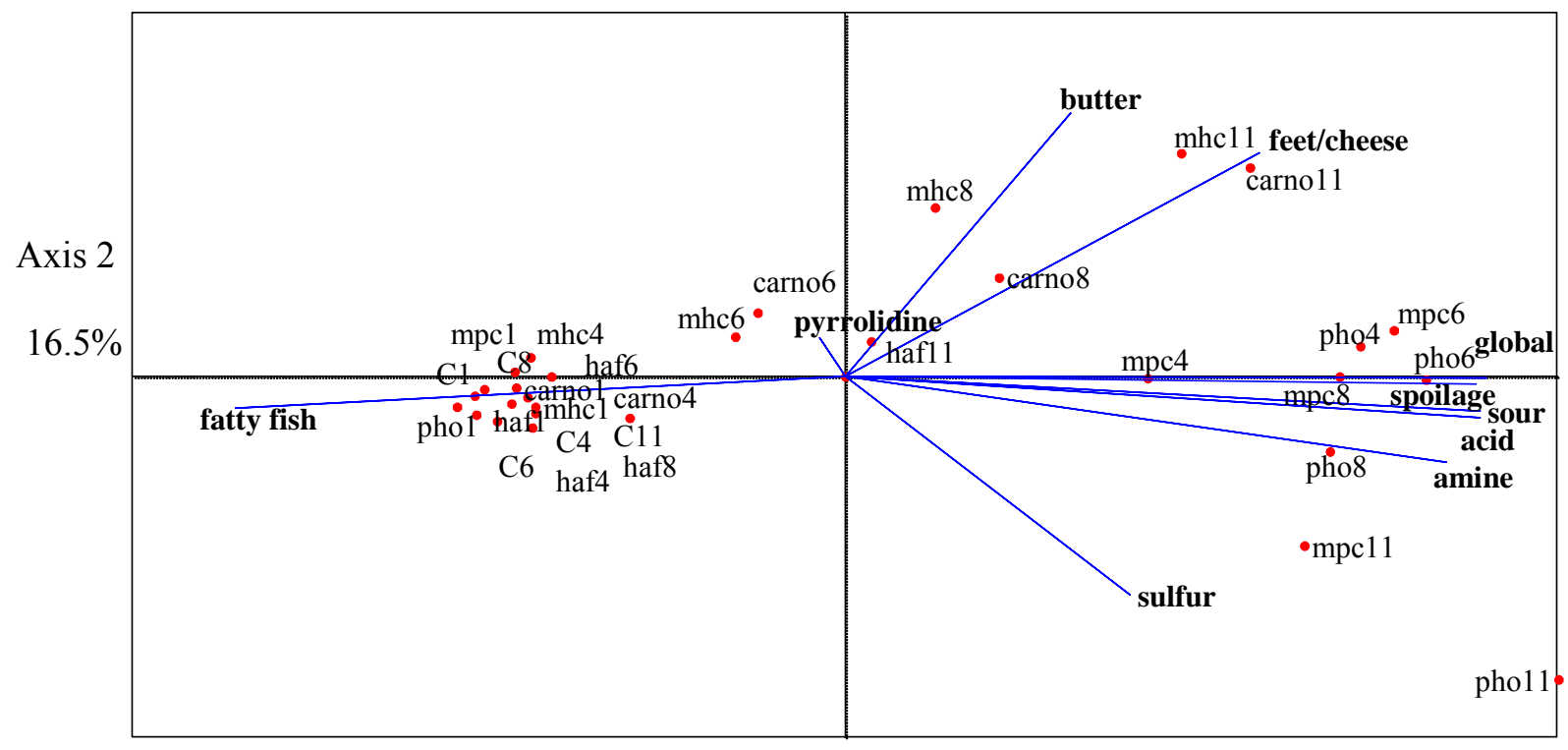

Axis $162.9 \%$

(B)

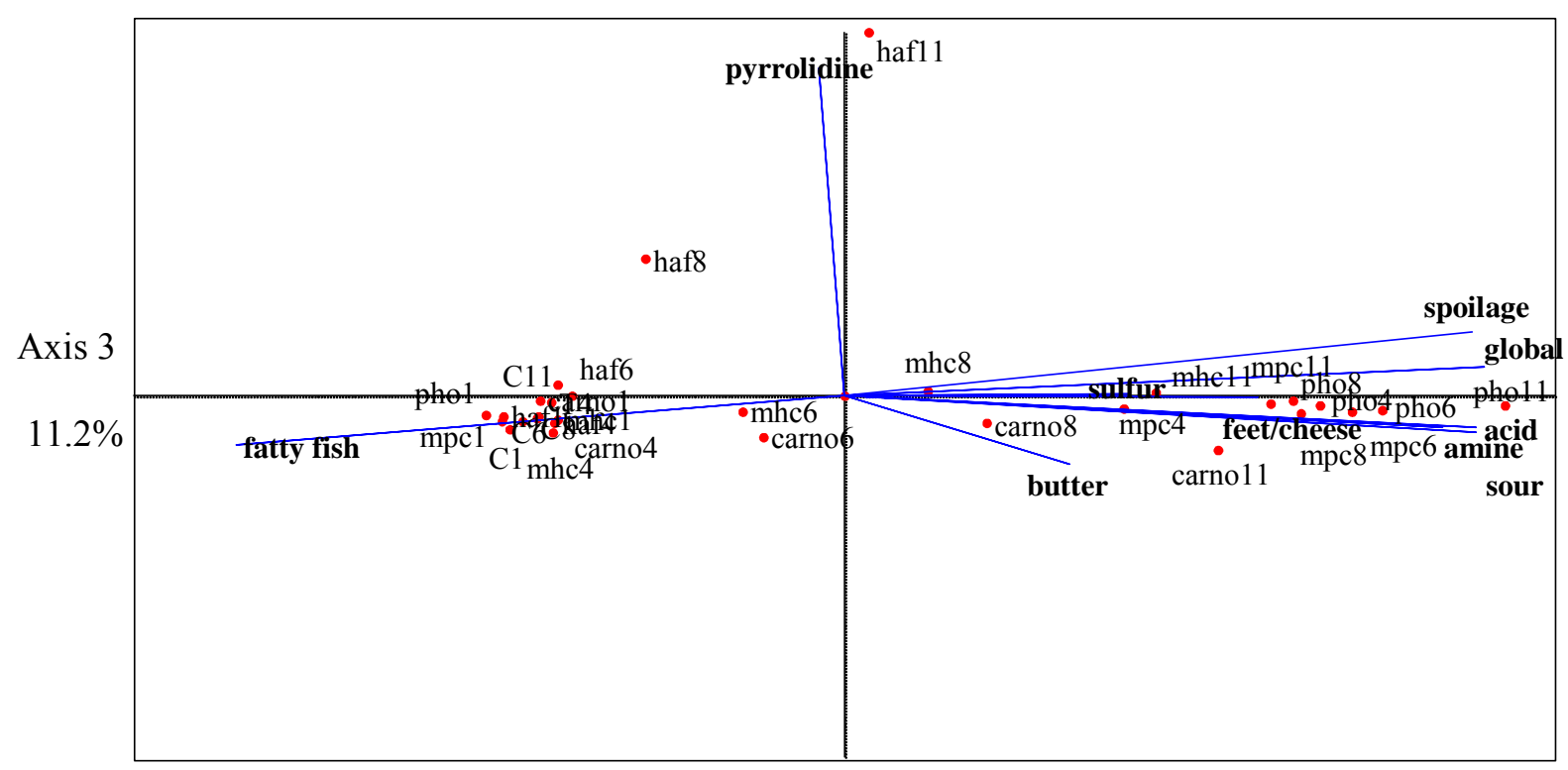

Axis $162.9 \%$ 
Figure 5. Development of (A) total volatile basic nitrogen (TVBN, mg-N $100 \mathrm{~g}^{-1}$ ) and (B) trimethylamine (TMA, mg-N $100 \mathrm{~g}^{-1}$ ) in raw salmon inoculated with different bacterial groups during MAP storage for 11 days at $8^{\circ} \mathrm{C}$.

(A)

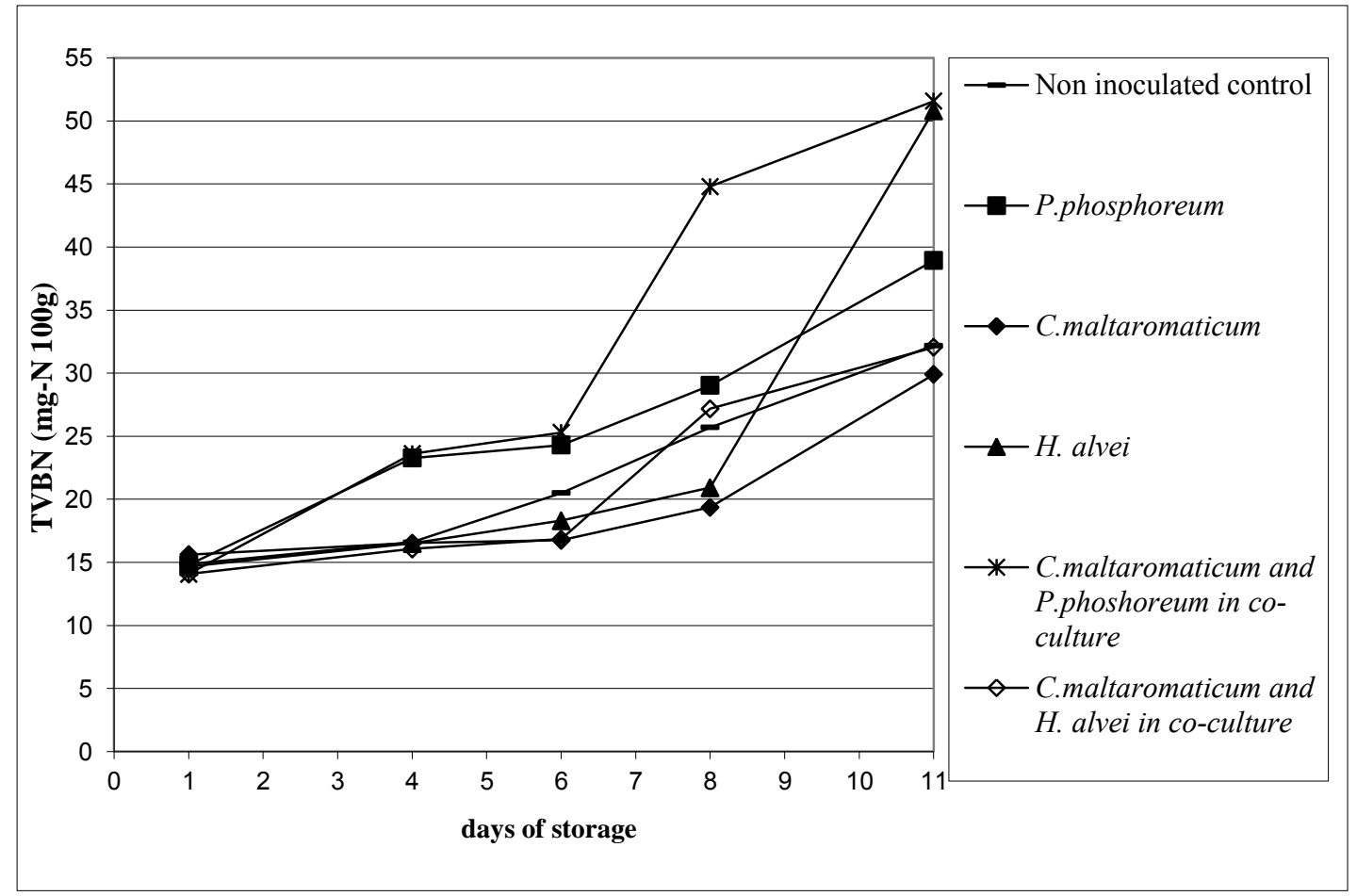

(B)

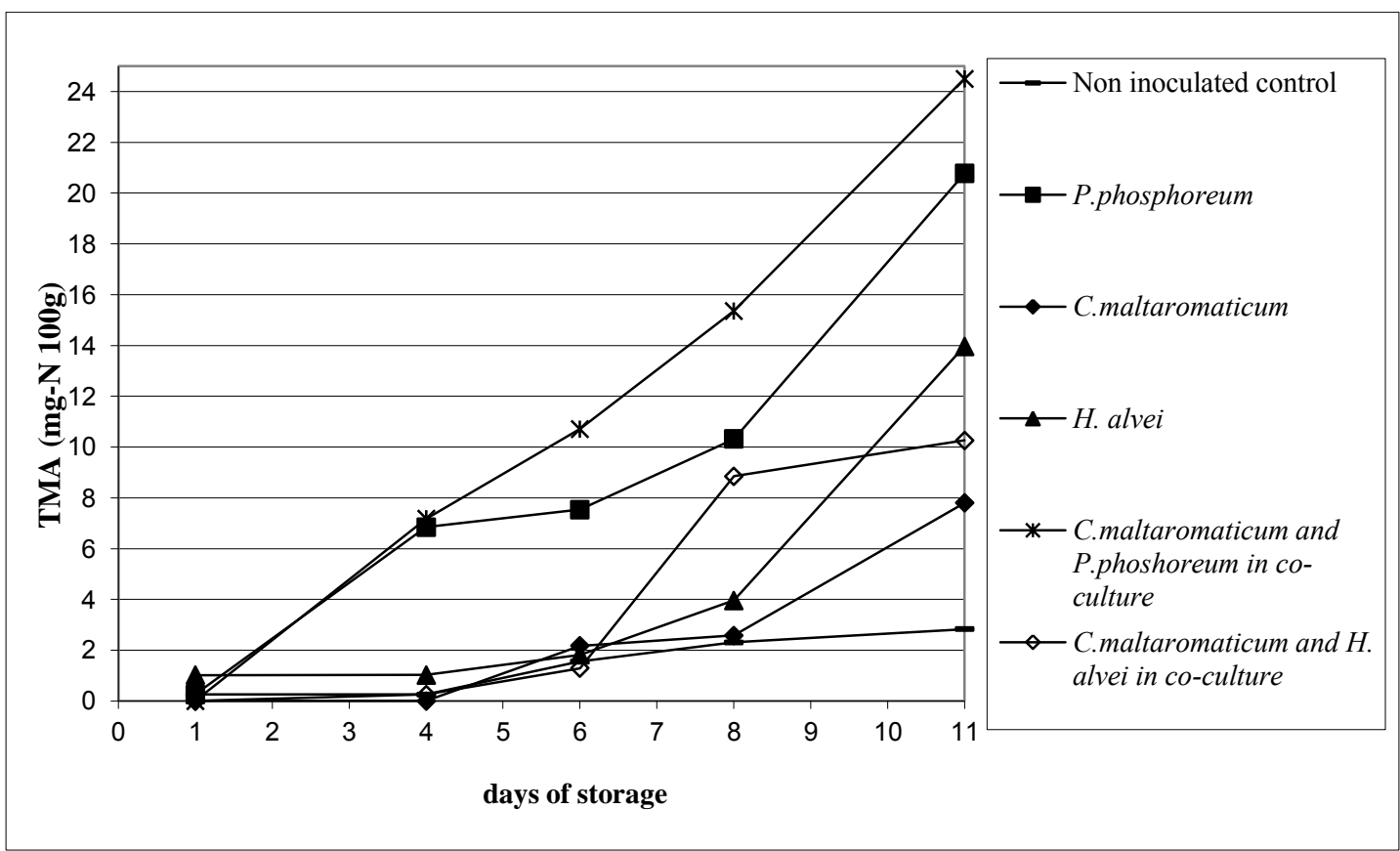


Figure 6. Fingerprints and dynamics of co-cultures inoculated on raw salmon during storage at $8^{\circ} \mathrm{C}$ for 11 days. Digitized TTGE profiles of $16 \mathrm{~S}$ rRNA gene V3 regions obtained by PCR amplification from bacterial DNA of 4 co-culture samples (day 4 , day 6 , day 8 , day 11 corresponding to lanes D4 to D11) from 2 different mixed cultures: $C$. maltaromaticum with $P$. phosphoreum (A) and C. maltaromaticum with $H$. alvei $(B)$ stored at $8^{\circ} \mathrm{C}$ for 11 days. Bands "C" have been assigned as C. maltaromaticum (A and B), bands "p1-p6" as $P$. phosphoreum (A) and bands "h1-h4" as $H$. alvei (B) by comparison with pure strain profiles.

(A)

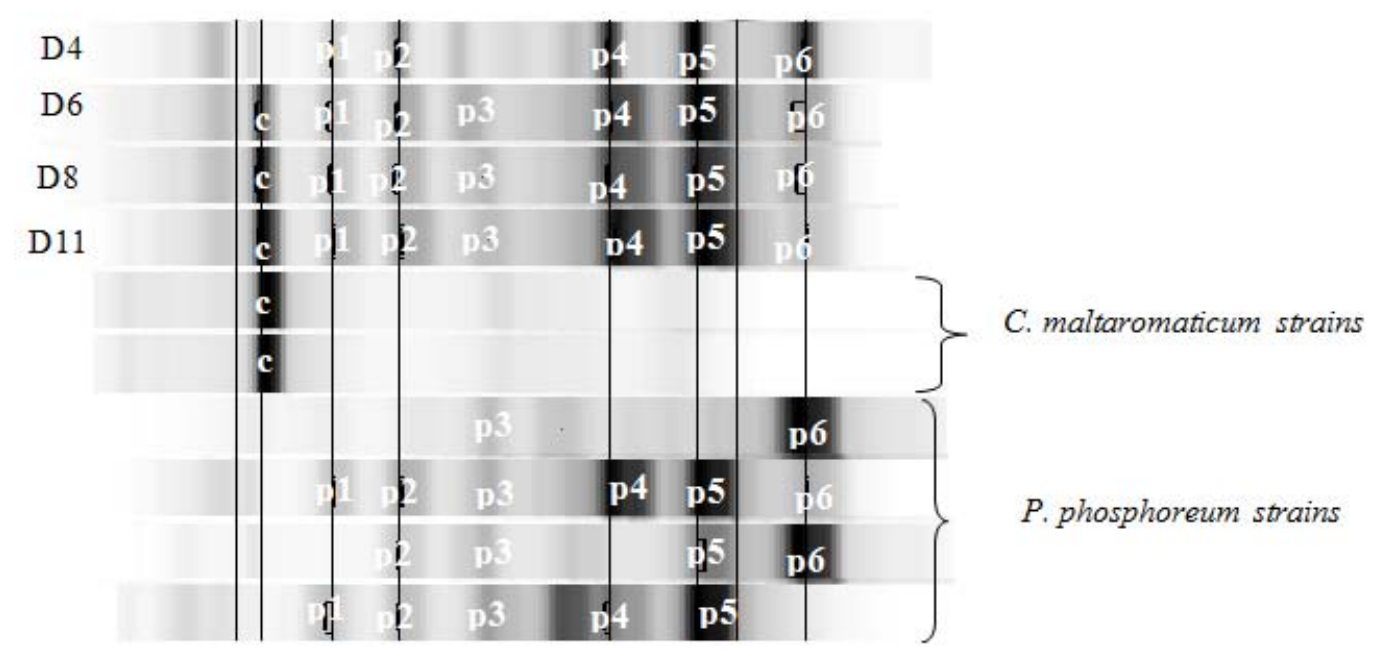

(B)

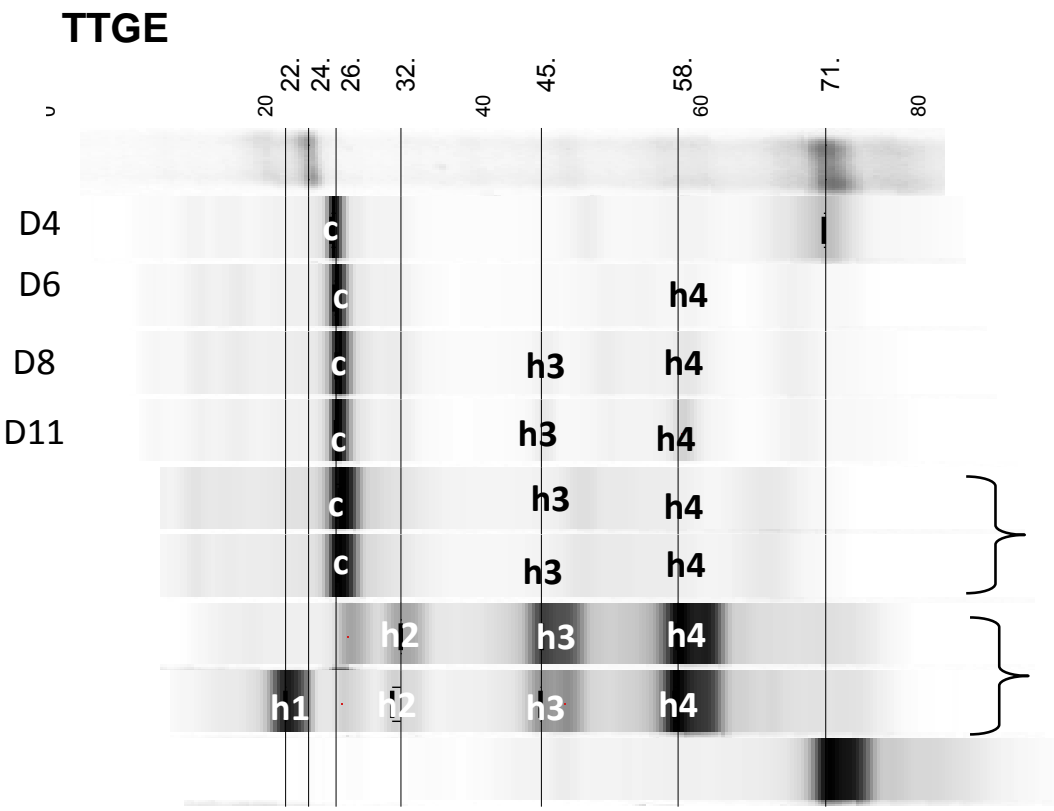

$\mathrm{C}+\mathrm{H} \mathrm{J} 11$

$\mathrm{C}+\mathrm{H}$ J4 1

$\mathrm{C}+\mathrm{H}$ J6 2

$\mathrm{C}+\mathrm{H}$ J8 1

$\mathrm{C}+\mathrm{H} \mathrm{J} 111$

MIP 2427

C. maltaromaticum strain MIP2415

MIP 2439

Mhiplyeistrains

témoin pcr souche dés de saı dés de sal dés de sal dés de sal dés de sal Carnobact Carnobact Hafnia alve Hafnia alve 